\title{
Estimation of Modal Properties of Low-Rise Buildings Using Ambient Excitation Measurements
}

\author{
K. K. Wijesundara, ${ }^{1}$ C. Negulescu, ${ }^{2}$ and E. Foerster ${ }^{3}$ \\ ${ }^{1}$ Faculty of Engineering, University of Peradeniya, Peradeniya 20400, Sri Lanka \\ ${ }^{2}$ BRGM (French Geological Survey), Natural Risks Division, 3 Avenue Claude Guillemin, 45060 Orléans Cedex 2, France \\ ${ }^{3}$ CEA Centre de Saclay, Bâtiment 603 Pièce 4, Point Courrier No 112, 91191 Gif-sur-Yvette Cedex, France \\ Correspondence should be addressed to C. Negulescu; c.negulescu@brgm.fr
}

Received 23 January 2015; Revised 27 May 2015; Accepted 8 June 2015

Academic Editor: Wei Xu

Copyright ( $2015 \mathrm{~K}$. K. Wijesundara et al. This is an open access article distributed under the Creative Commons Attribution License, which permits unrestricted use, distribution, and reproduction in any medium, provided the original work is properly cited.

\begin{abstract}
Continuous wavelet transform (CWT) has recently emerged as a promising tool for identification of modal properties through ambient excitation measurements of structures. However, it is difficult to obtain an accurate estimation of damping ratio directly from time-frequency decomposition of ambient vibration measurements using CWT. The main objective of this study is to introduce a new method called two-step procedure in the estimation of damping ratios using ambient vibration measurements. The two-step procedure involves the development of random decrement (RD) signature from the ambient vibration measurements, which is equivalent to the damped free vibration response of a structure under a given initial displacement and subsequently decomposition of time domain RD signature into time-frequency domain using CWT. The secondary objective of the study is to show that CWT is capable of identifying the natural periods and mode shapes of low-rise buildings using ambient vibration measurements. Furthermore, the two-step procedure is validated with two practical applications in a five-storey reinforced concrete structure with masonry infill walls and a three-storey masonry structure. Finally, a conclusion can be drawn that the two-step procedure yields a reasonably good estimation of damping ratio.
\end{abstract}

\section{Introduction}

Currently, ambient vibration measurements are used in the assessment and structural health monitoring of civil engineering structures such as buildings, bridges, and towers $[1,2]$. An ambient vibration measurement is actually an acceleration or velocity measurement by an accelerometer or seismometer, respectively, during the vibration of a structure induced by mild wind loadings, traffic loadings, or machine vibration. An ambient vibration measurement is cheap and fast, no elaborate excitation equipment is required, and no boundary condition simulations are required. Furthermore, modal properties of the whole system can be estimated using a modal extraction technique. The extracted modal parameters such as natural periods, mode shapes, and damping ratios can also be used for verifying the design characteristics of a civil engineering structure and validating the numerical model that can be used to predict the response of a structure under an extreme loading condition.

Many modal extraction techniques found in the literature, which are developed to estimate the modal properties using only the output response, can be categorized into three main groups as time domain, frequency domain, and timefrequency domain methods. The frequency domain methods such as frequency domain decomposition (FDD) $[3,4]$ and enhanced frequency domain decomposition (EFDD) $[3,4]$ are commonly used for the extraction of natural periods and their mode shapes, but uncertainty in the estimation of damping ratios is quite significant. In general, time domain methods such as random decrement (RD) method [5], Ibrahim time domain (ITD) [6], and the eigensystem realization algorithm (ERA) [7] are widely used in damping estimation. The major problem associated with many time domain methods is how to distinguish structural modes from 
uncorrelated modes. This problem can cause severe error in damping estimation.

Recently, continuous wavelet transform (CWT) method is used for modal identification of civil engineering structures using only the output response as a time-frequency domain method. As the CWT method can decompose a signal into time-frequency domain using a mother wavelet, multi-degree-of-freedom (MDOF) systems can be handled directly. Furthermore, it can work as a band-pass filter and, hence, this method can handle very noisy measurements [8]. Another advantage of the CWT method is that the stationary assumption for an ambient vibration measurement is not required. Therefore, this method has many advantages over the other methods in identifying modal properties using ambient vibration measurements. This method has been used successfully to extract the natural periods and their mode shapes using ambient vibration measurements of a structure $[1,2]$. Regarding the damping estimation, the past studies by Staszewski [8], Hans et al. [9], Lamarque et al. [10], and Ta and Lardis [11] have highlighted that damping ratios can be estimated adequately accurately through wavelet-based logarithmic decrement for lightly damped system. However, their studies are limited to either the impulse response or damped free vibration of structures.

Therefore, the main objective of this study is to introduce a new method called two-step procedure in the estimation of damping ratios using ambient vibration measurements. In the first step of the two-step procedure, a damped free vibration response of a structure is evaluated from the ambient vibration measurement using RD method. In the second step, the damped free vibration is then decomposed into time-frequency domain using CWT with Morlet wavelet to estimate damping ratios. The secondary objective of the study is to show that CWT is capable of identifying the natural periods and their mode shapes of low-rise buildings directly using ambient vibration measurements. However, it is worth noting that, in this study, single step procedure is used to extract natural periods and their mode shapes by decomposing of the ambient vibration measurement of a structure into the time-frequency domain using the CWT method.

This study also discusses the capability of the two-step procedure to identify damping ratios accurately using a numerical application in five-storey frame structure. For this purpose, 2D numerical model of a five-storey reinforced concrete frame is analysed linear elastically for 50 -scaled real earthquakes. Acceleration time histories obtained at the top storey level are used as ambient vibration measurements to estimate the damping ratios using the two-step procedure. It must be noted that, in the numerical model, $5 \%$ damping ratio is assigned for all the five modes of vibration. Then, the damping ratios of dominant modes of vibrations estimated using the two-step procedure are compared with the numerically assigned damping ratios.

Furthermore, dominant modes of vibrations and their periods are extracted by decomposing of the acceleration time histories into time-frequency domain using CWT and subsequently they are compared with the natural periods and their mode shapes of vibrations obtained from the modal analysis of the numerical model. Finally, this study presents the modal properties extracted through ambient vibration measurements of two case study buildings.

This paper is organized in the following form: in Section 2, the RD technique is discussed briefly. In Section 3, the continuous wavelet transform and its properties are introduced. In Section 4, a numerical example is presented to emphasize the capability of CWT method to estimate the modal properties. In Section 5, modal properties of two case study buildings extracted through ambient vibration responses using CWT method are presented. This paper is briefly concluded in Section 6.

\section{Random Decrement (RD) Method}

The Random decrement (RD) method proposed by Cole [5] is a commonly used approach in estimation of damping ratio using the ambient vibration measurement of a structure because it is computationally very efficient. A RD signature, which represents the response equivalent to the damped free vibration response of a structure, is evaluated using the sampling method that time segments extracted with a common initial or triggering condition and the duration as shown in Figure 1 from the ambient vibration measurement are averaged. In general, the response of a dynamic system is composed of three response components. They are the responses due to both the initial displacement and the velocity and the force vibration response.

The intention of using the sampling technique is that averaging time segments of the ambient vibration measurement of a structure with a common triggering condition is to reduce the initial velocity response and the forced vibration response to zero. As number of segments increases, the ensemble average of the forced vibration response tends to zero. If all segments in the average begin at the same threshold level and alternating positive and negative slope, then the response due to initial velocity is averaged out while the response due to initial displacement remains [12]. Based on this explanation, the RD signature is equivalent to a damped free vibration response of a structure to an initial displacement equivalent to the selection amplitude. The $\mathrm{RD}$ signature $\delta_{t}$ is expressed by Yang et al. [12] as

$$
\delta_{t}=\frac{1}{N} \sum_{i=1}^{N}\left(x_{i,\left(t_{i}+r\right)}\right),
$$

where $N$ is the number of segments used to evaluate the RD signature. This initiative explanation has been used in much of the available literature in damping estimation and seems to be reasonable for linear systems [13]. However, Vandiver et al. [14] and Bedewi [15] have proved mathematically that if the input force vector is a stationary Gaussian random process with zero means, then the RD signatures of displacement responses of the system are equivalent to the damped free vibration. Furthermore, Huang et al. [16] mathematically showed that only Gaussian white-noise input could make the $\mathrm{RD}$ signatures equivalent to the damped free response. Huang and Yeh [17] provide theoretical properties which is useful to understand the characteristics of the $\mathrm{RD}$ signatures. 


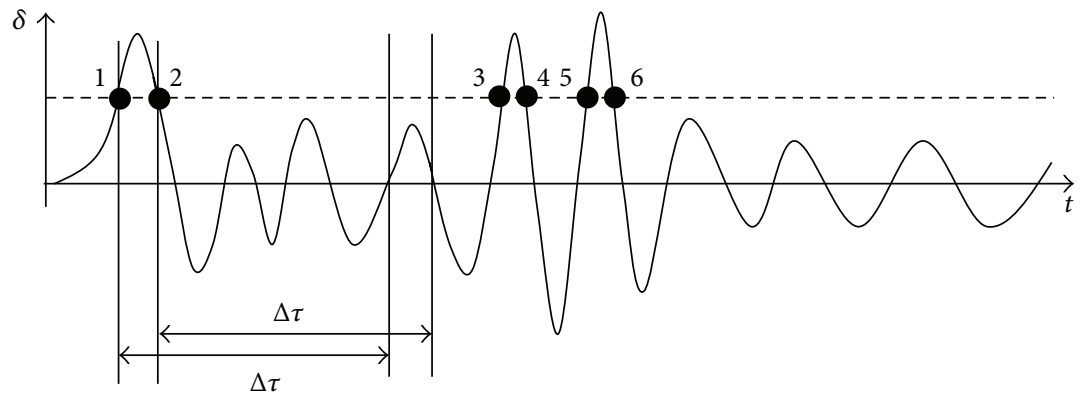

(a) Ambient vibration measurement

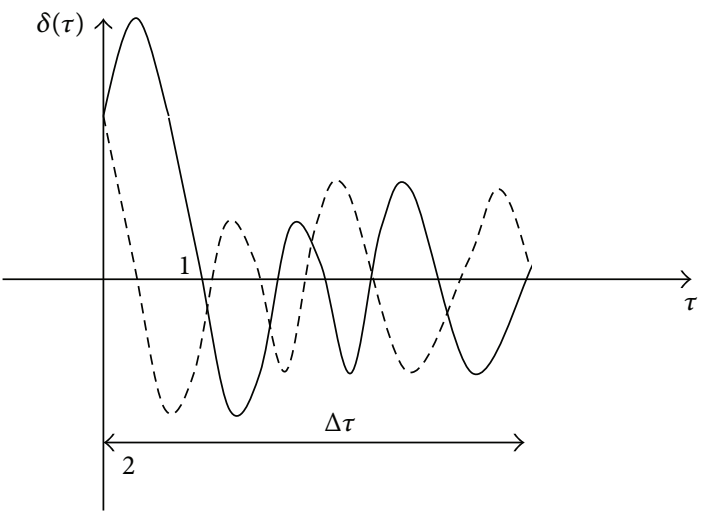

(b) Time segments

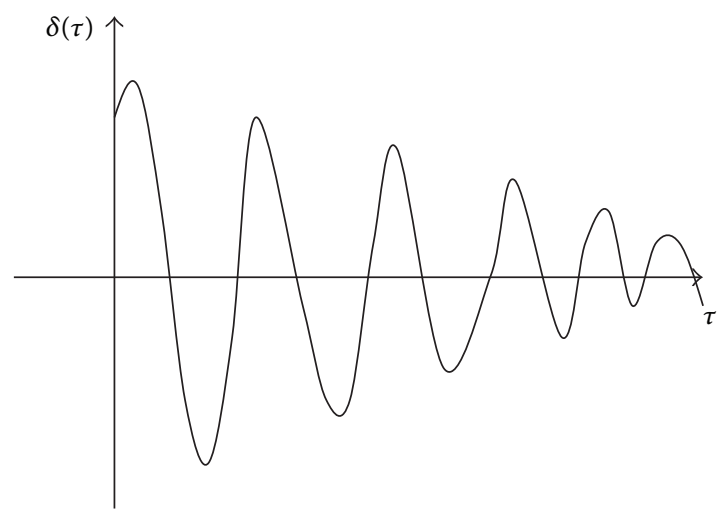

(c) Random decrement signature

FIgURE 1: Procedure to obtain random decrement $(\mathrm{RD})$ signature from an ambient vibration response.

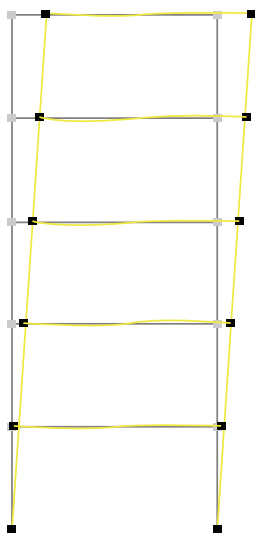

Mode 1

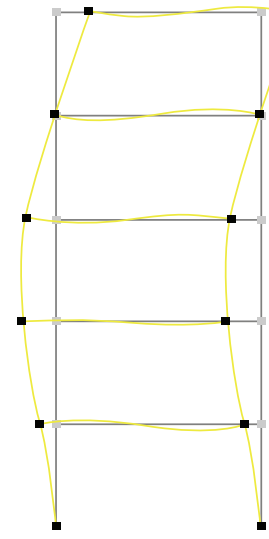

Mode 2

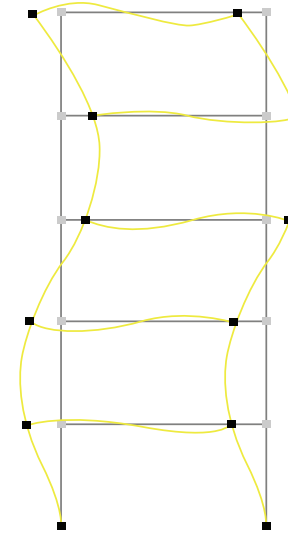

Mode 3

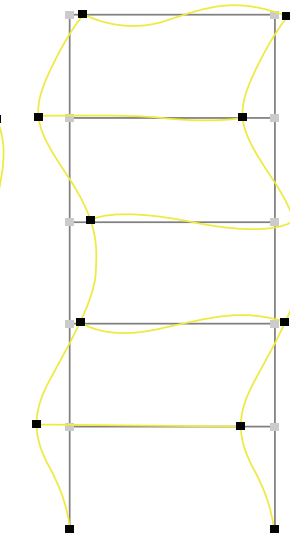

Mode 4

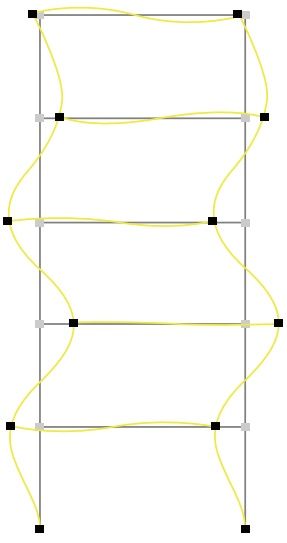

Mode 5

Figure 2: Mode shapes of the five translational modes.

\section{Continuous Wavelet Analysis}

This section introduces a brief description on the theoretical background of the wavelet transform. However, authors strongly recommend to readers referring to the key papers to understand the theoretical background of the method well. The basic idea of the CWT is to find a function $\psi(t)$, which can generate a basic for the entire domain of a function $x(t)$, if the function $\psi(t)$ satisfies the condition that $\psi(t)$ decays to zero at positive and negative infinity as in the case of
Fourier transform. The fast decay in time domain and the limited bandwidth in frequency domain introduce locality into the analysis, which is not the case of Fourier transform where a global representation can only be obtained. The function $\psi(t)$ is called a mother wavelet. Then, using a mother wavelet, CWT can be used to decompose a function $x(t)$ into frequency-time domain as defined in the following form:

$$
W_{(a, b)}=\frac{1}{\sqrt{a}} \int_{-\infty}^{+\infty} x(t) \psi^{*}\left(\frac{t-b}{a}\right) d t
$$




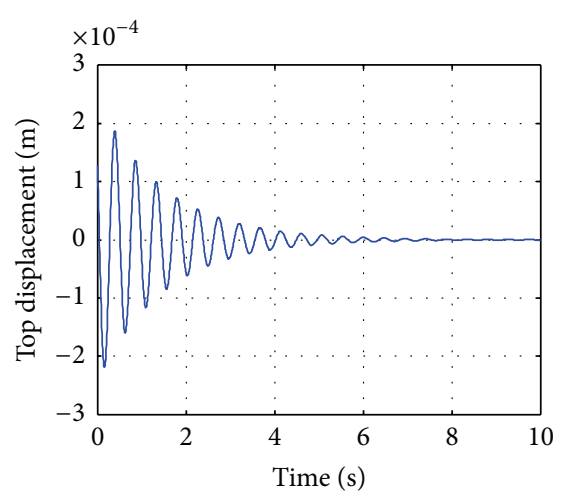

(a)

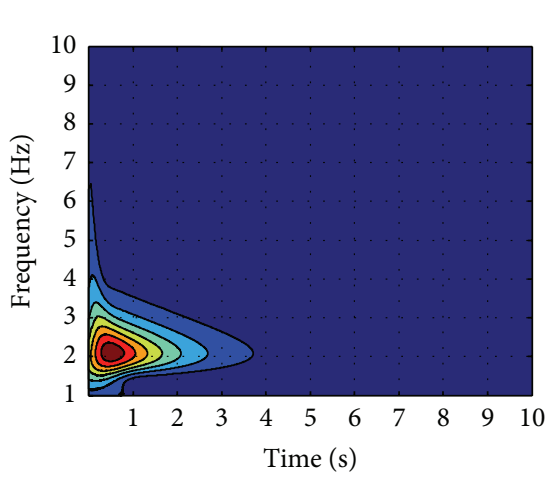

(b)

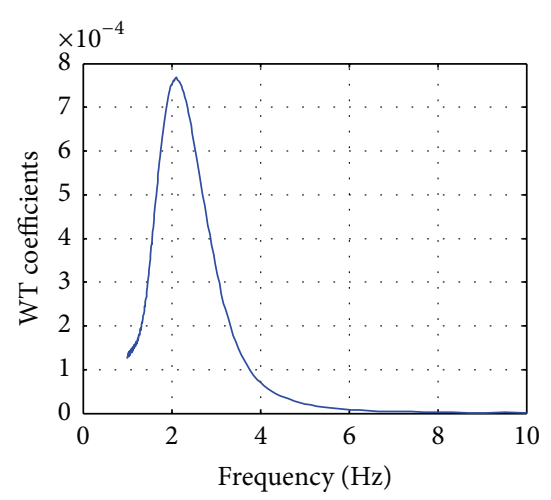

(c)

Figure 3: (a) Free decay response at top story, (b) its time-frequency resolution, and (c) the extracted window parallel to frequency axis at the wavelet ridge.

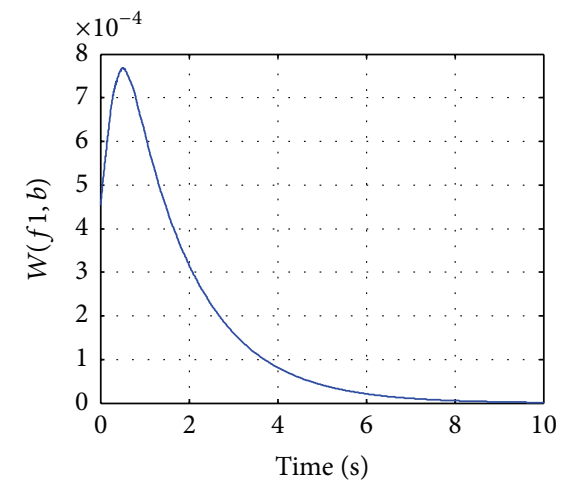

(a)

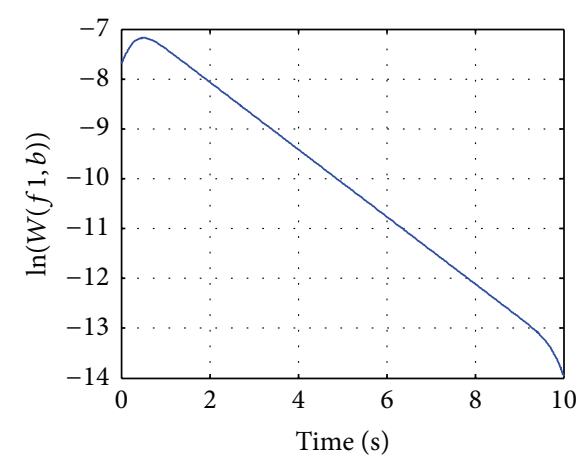

(b)

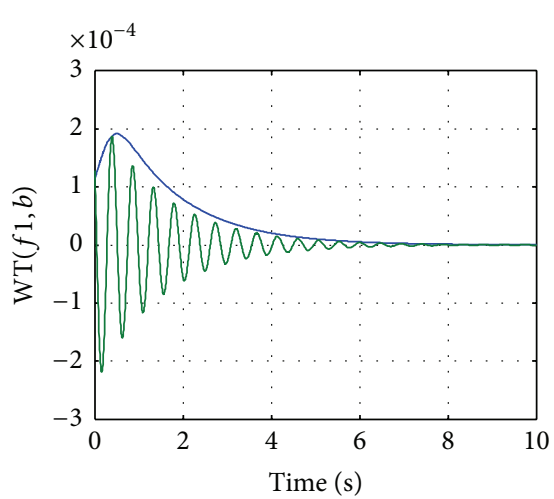

(c)

FIgURE 4: (a) The extracted envelope parallel to frequency axis at the wavelet ridge, (b) semilogarithmic plot of the envelope, and (c) comparison of free decay response and the wavelet envelope.

where $\psi^{*}(t)$ and $b$ are the complex conjugate of $\psi(t)$ and the parameter localizing the wavelet function in the time domain, respectively. $W_{(a, b)}$ are the CWT coefficients that represent the measure of the similitude between the function $x(t)$ and the wavelet at the time $b$ and the scale $a$. The complex Morlet wavelet is commonly used for continuous wavelet transform as a mother wavelet.

\subsection{Estimation of Damping Ratio Using Wavelet Transform.} The dynamic equilibrium equation of a SDOF system can be expressed as

$$
m \ddot{x}+c \dot{x}+k x=f(t),
$$

where $m, c$, and $k$ are mass, damping and the stiffness of the SDOF system. Considering the SDOF system as described by (3), the damped free vibration of an underdamped system can be represented in the following form:

$$
x(t)=A(t) e^{ \pm i \omega_{n} \sqrt{1-\zeta^{2}} t}=A(t) e^{i \phi(t)},
$$

where $A(t)$ is the decaying envelope of the free vibration response of the SDOF system. It can also be expressed in the following form:

$$
A(t)=A_{0} e^{-\zeta \omega_{n} t},
$$

where $\varsigma$ is damping ratio and $A_{0}$ is the initial amplitude of the response. For the Morlet wavelet function, the modulus of CWT coefficients can be approximated as [8]

$$
\left|W_{(a, b)}\right| \approx A(b)\left|G^{*}(a(\dot{\phi}(b)))\right| .
$$

Combining (4), (5), and (6) and given value of $A_{0}$, the following relationship can be determined:

$$
\left|W_{\left(a_{0}, b\right)}\right| \approx A_{0} e^{-\varsigma \omega_{n} b}\left|G^{*}\left( \pm a_{0} i \omega_{n} \sqrt{1-\varsigma^{2}}\right)\right| .
$$

When the logarithm is applied to (7), a simple calculation gives

$$
\ln \left|W_{\left(a_{0}, b\right)}\right| \approx-\varsigma \omega_{n} b+\ln \left(A_{0}\left|G^{*}\left( \pm a_{0} i \omega_{n} \sqrt{1-\varsigma^{2}}\right)\right|\right) .
$$




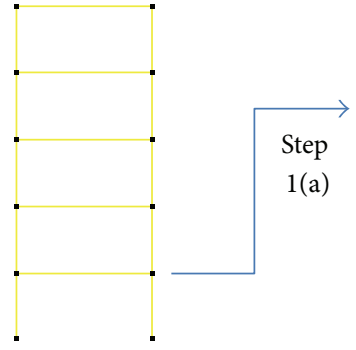

(a)

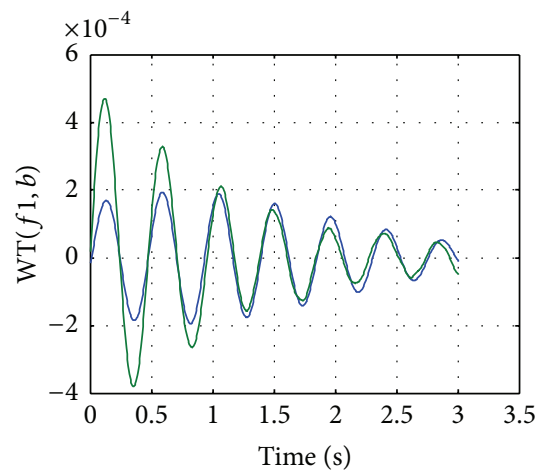

(d)

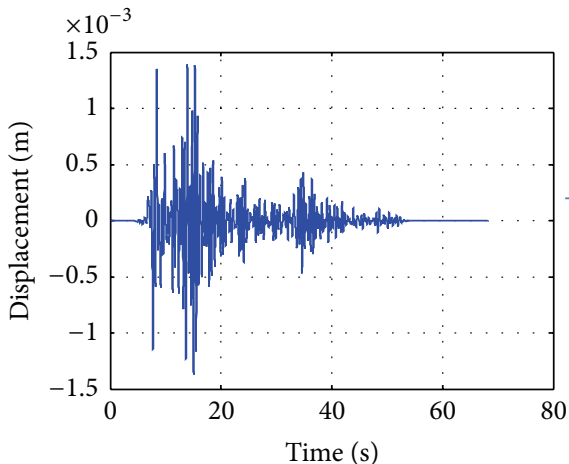

(b)

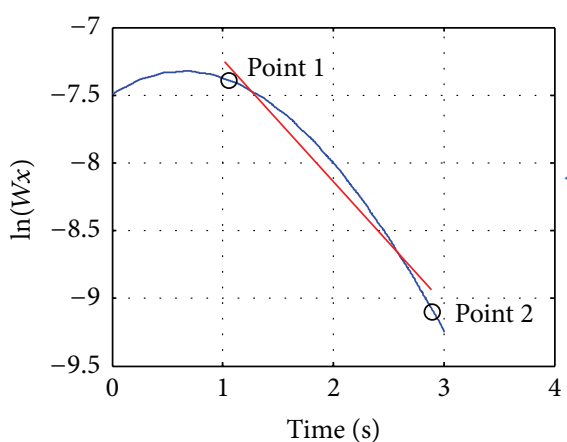

(e)

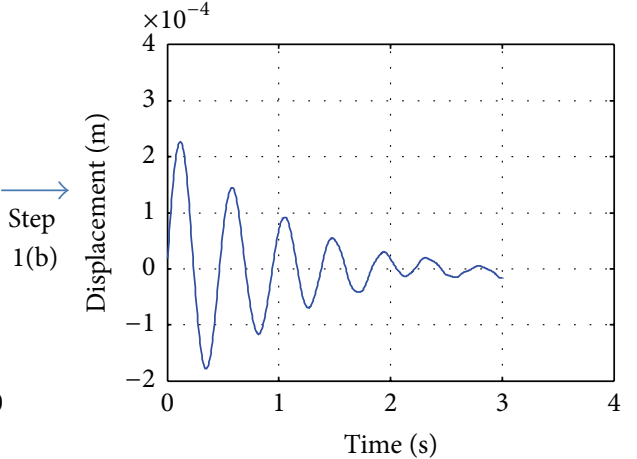

(c)

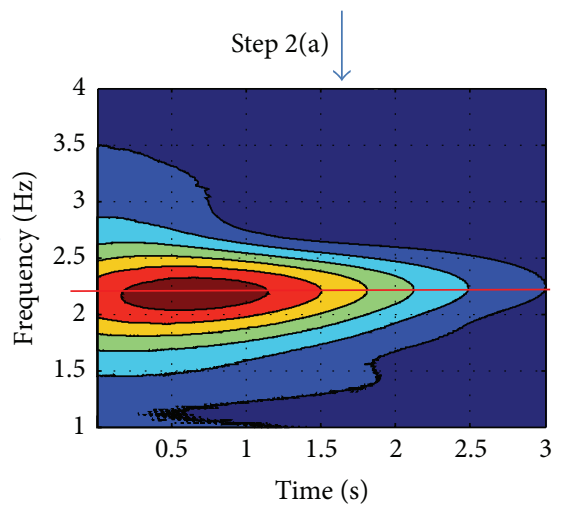

(f)

FIGURE 5: The two-step procedure for estimation of damping ratio.

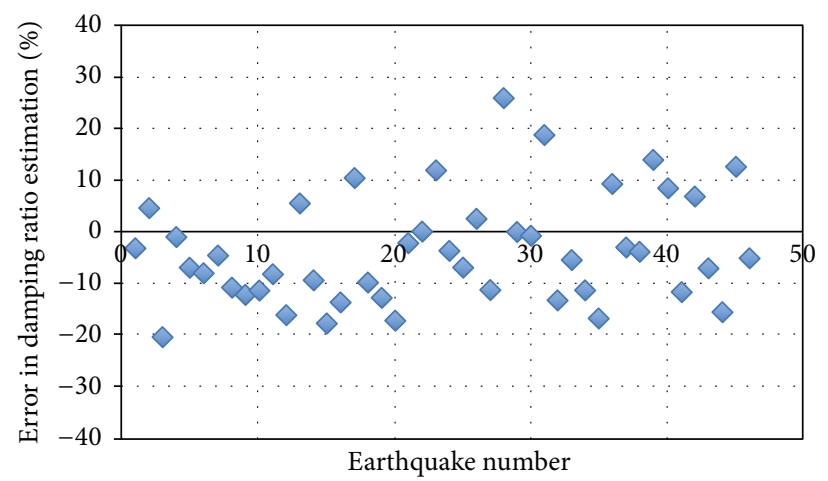

FIGURE 6: Variation of error in estimation of damping ratio for different earthquake responses.

Therefore, the damping ratio $\varsigma$ of the system can be estimated from the slope of the straight line of the wavelet modulus cross using

$$
\varsigma=\frac{1}{2 \pi m} \ln \left|\frac{W_{\left(a_{0}, b\right)}}{W_{\left(a_{0}, b+m T_{0}\right)}}\right| .
$$

The wavelet ridges are formed at an instantaneous frequency and time when the frequency of the response at a time is equal to the frequency of the dilated mother wavelet.
Therefore, natural periods are evaluated from extracting a window parallel to the frequency axis of time-frequency plot at wavelet ridges where the CWT coefficients reach their maximum values.

Mode shapes are estimated through the wavelet transforms of output response at point $k$ and the reference point as shown below:

$$
\phi_{i}^{k}=\frac{W_{\left(a_{i}, b\right)}^{k}}{W_{\left(a_{i}, b\right)}^{\mathrm{ref}}} .
$$




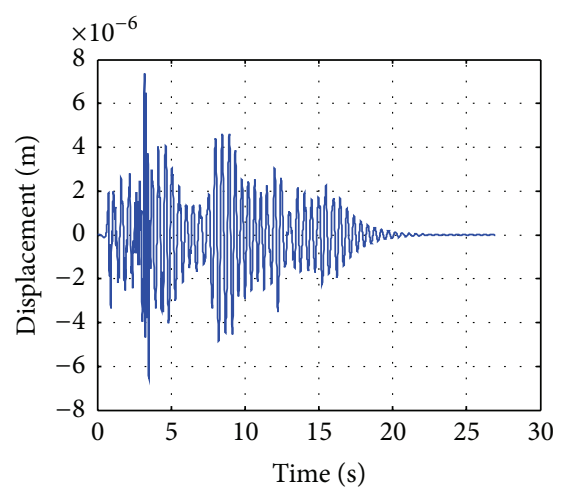

(a)

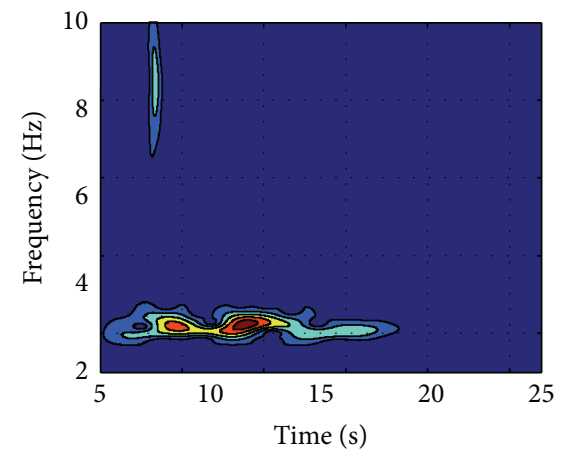

(b)

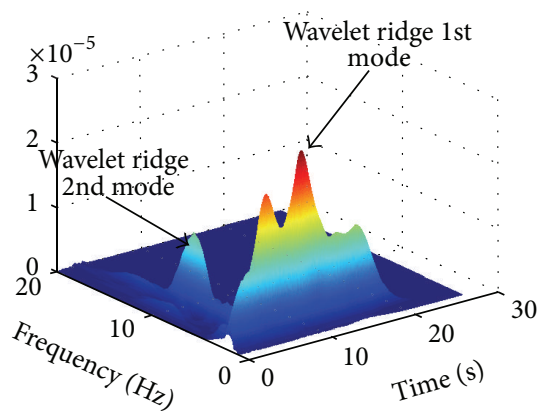

(c)

Figure 7: (a) The displacement response at top story level, (b) its time-frequency plot, and (c) wavelet ridges.

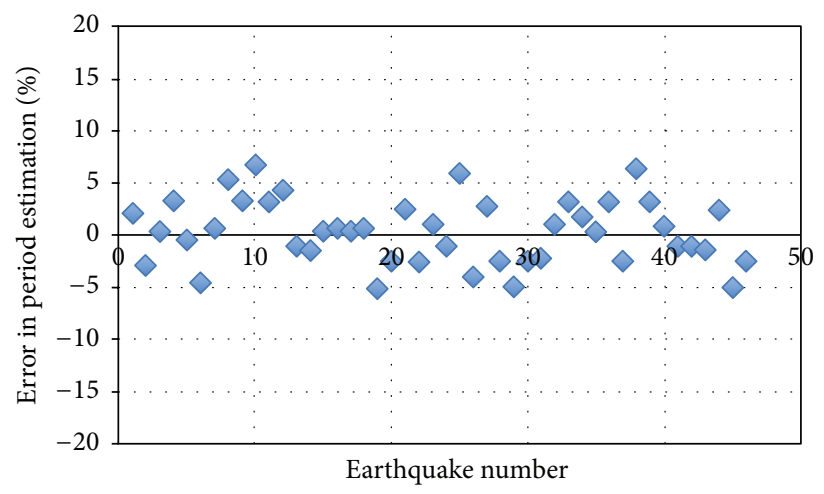

FIGURE 8: Variation of error in estimation of period for different earthquake responses.

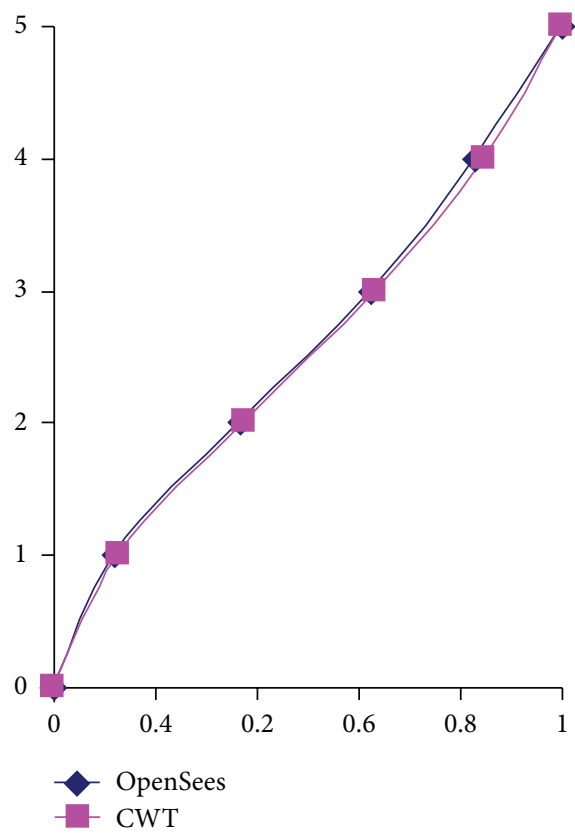

Mode 1

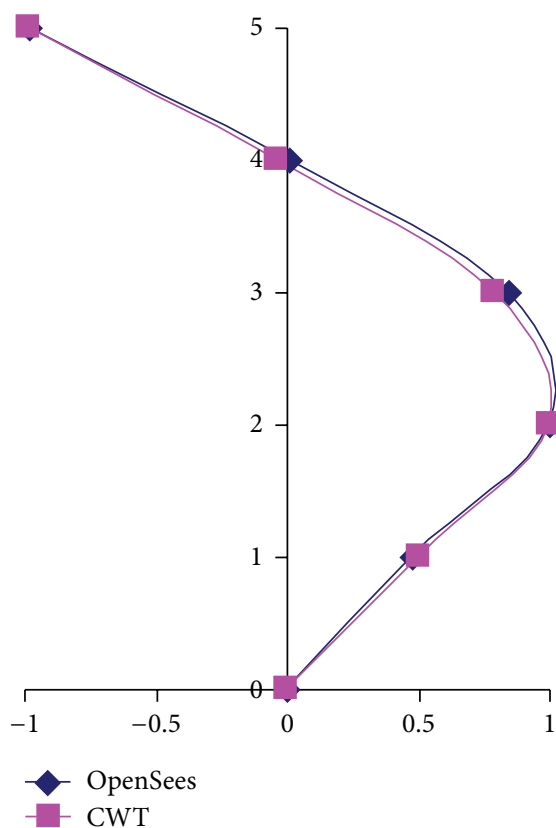

Mode 2

FIGURE 9: Comparison of the mode shapes obtained using numerical model and the CWT. 


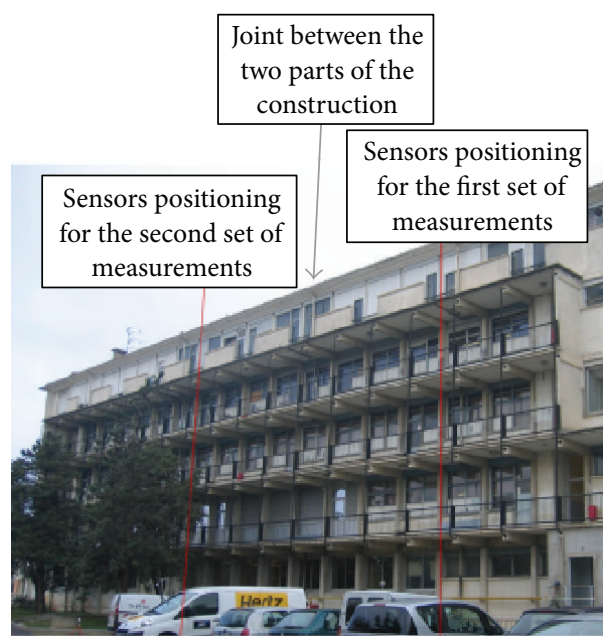

(a)

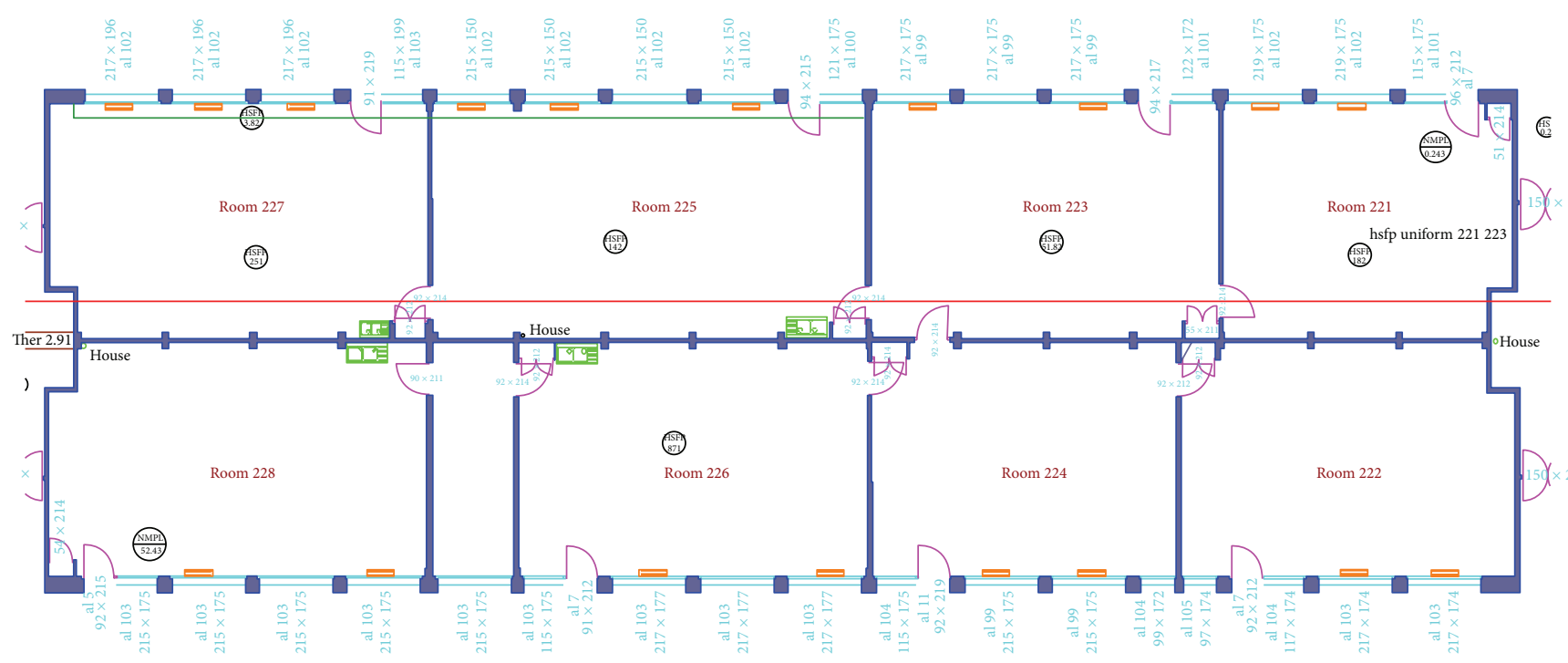

(b)

Figure 10: (a) 3D view and (b) plan view of Picasso building.

\section{Numerical Application in a Five-Storey Frame}

However, if the response is not free decay, then the twostep procedure is used to estimate the damping ratio in this study. This procedure may cause severe error in damping estimation when the response is recorded in a relatively short duration because $\mathrm{RD}$ signatures evaluated in the first step of the procedure may not be proportional to the free decay response as discussed in Section 2 briefly. Therefore, the main objective of this section is to quantify the error associated with estimation of damping ratio using the twostep procedure from an ambient vibration response recorded in a relatively short duration.

The secondary objective is to quantify the error associated with estimation of natural periods and their mode shapes from an ambient vibration recorded in a relatively short duration. It must be noted that natural periods are estimated using single step procedure by extracting a window parallel to the frequency axis of time-frequency plot at wavelet ridges as described in Section 3. For these purposes, a five-storey reinforced concrete building that has single bay of $6 \mathrm{~m}$ width in transverse direction while having 16 bays with the equal bay width of $3 \mathrm{~m}$ in the longitudinal direction is selected for this study. The height of each storey is $3.0 \mathrm{~m}$. A twodimensional (2D) finite element model, which represents an interior frame in transverse direction of the reinforced concrete frame building, is developed using OpenSees finite element program in order to estimate natural periods and their mode shapes in transverse direction of the building. It consists of frame elements to represent all the beams and columns, respectively. Dimensions of all the columns are $300 \mathrm{~mm}$ in width and depth. Dimensions of all the beams are $300 \mathrm{~mm}$ in width and $600 \mathrm{~mm}$ in depth. Base nodes of the model are fixed by restraining all the three degrees of freedom. The 2D numerical model is analysed linearly 

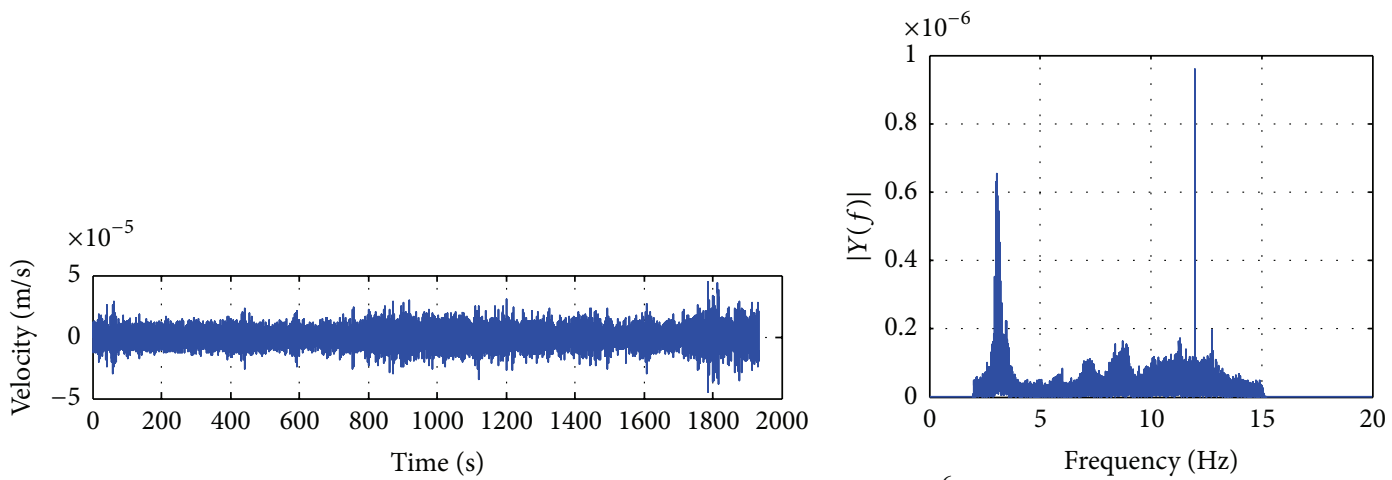

Filtered velocity time history at ground floor
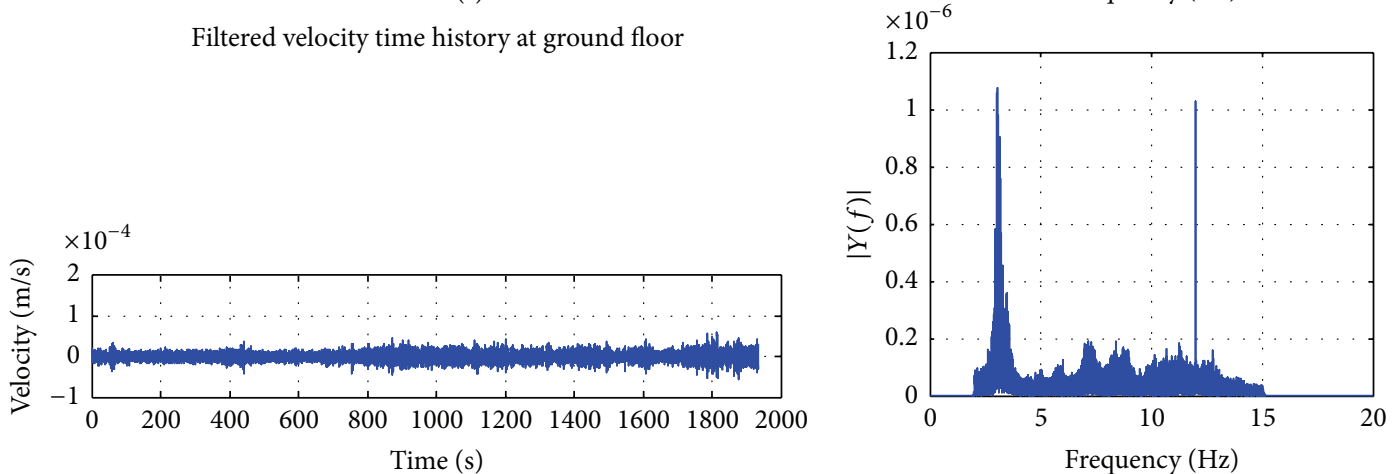

Filtered velocity time history at first floor
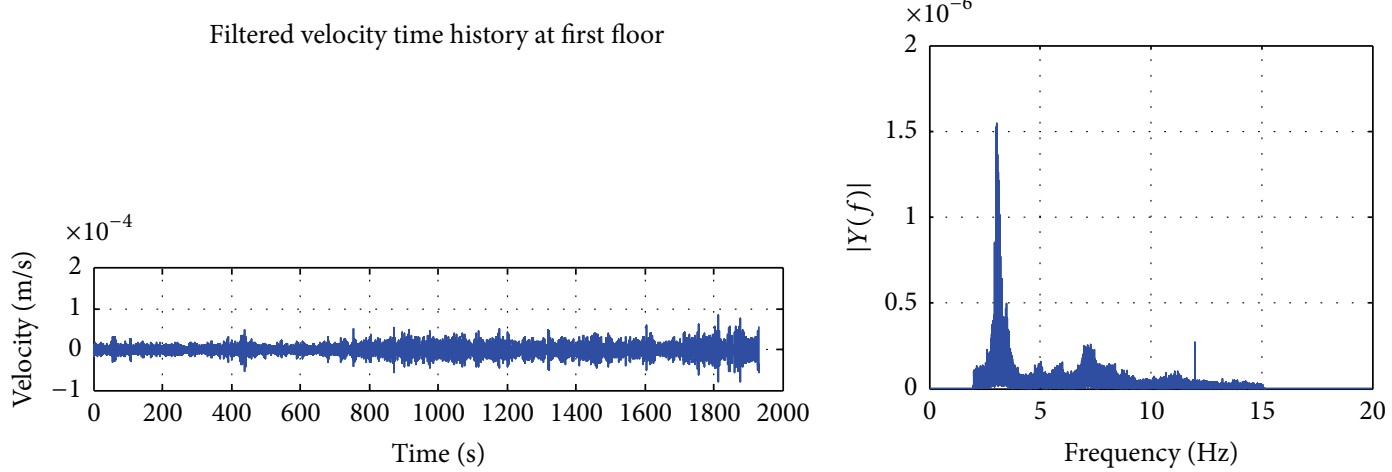

Filtered velocity time history at second floor

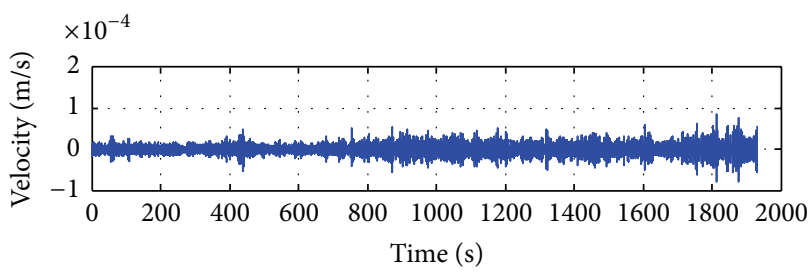

Filtered velocity time history at third floor

(a)

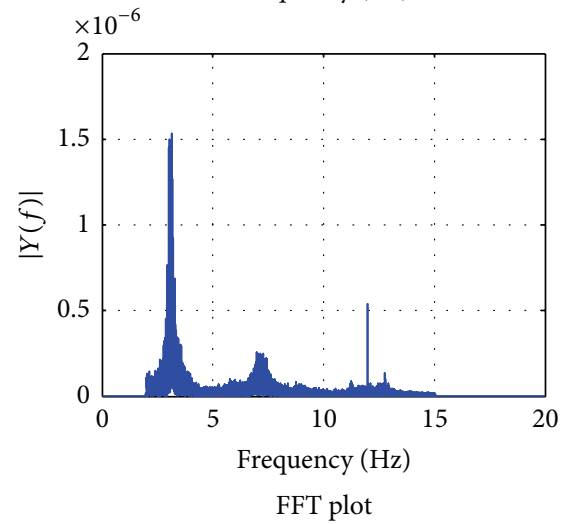

(b)

FIGURE 11: (a) Filtered velocity time histories at each floor in E-W direction and (b) their fast Fourier transformation (FFT) plots.

elastically for 50 ground motions, recorded during the past earthquakes. Newmark constant average acceleration time integration scheme is used for the time history analysis. The stiffness proportional damping with $5 \%$ of critical damping for all the modes of vibration is assumed in the numerical model. From the modal analysis, the identified frequencies of the five translational modes are $2.1,8.2,16.1,27.8$, and $38.5 \mathrm{~Hz}$. Figure 2 illustrates the five translational mode shapes. 

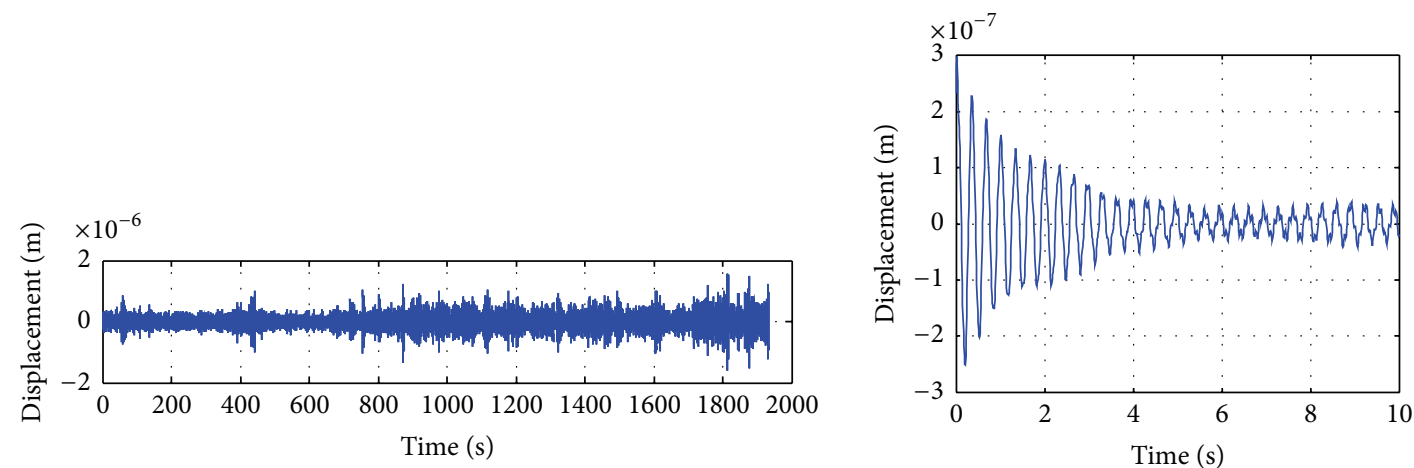

Integrated displacement time history at ground floor
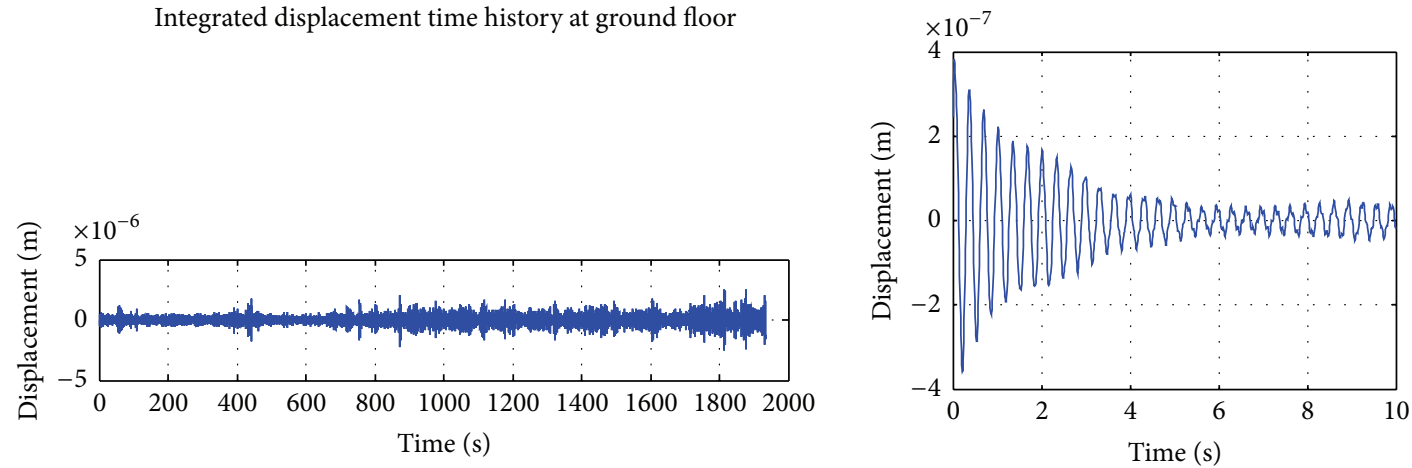

Integrated displacement time history at first floor
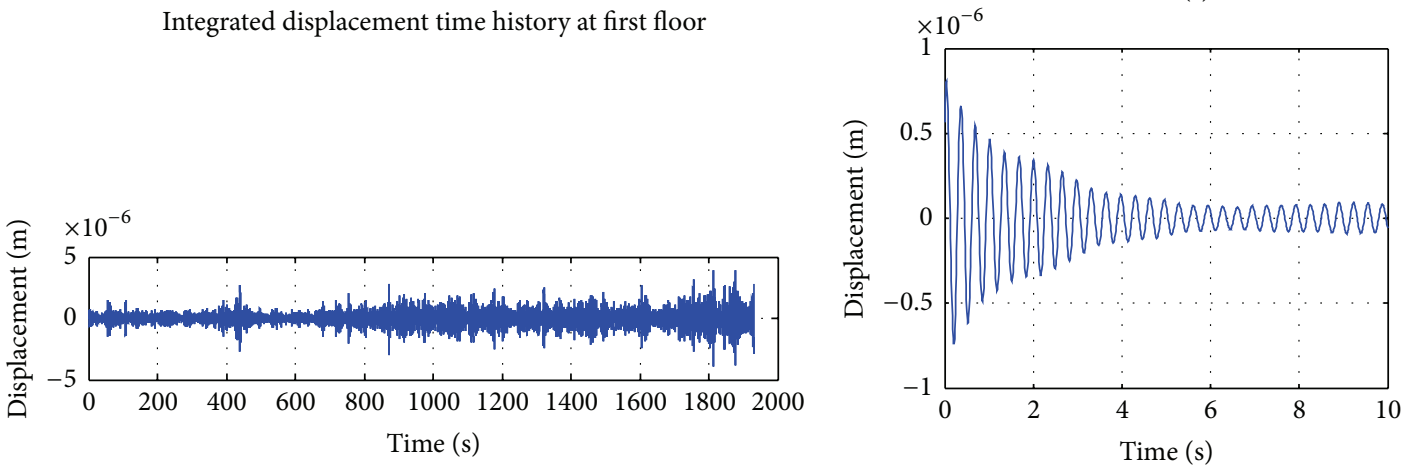

Integrated displacement time history at second floor

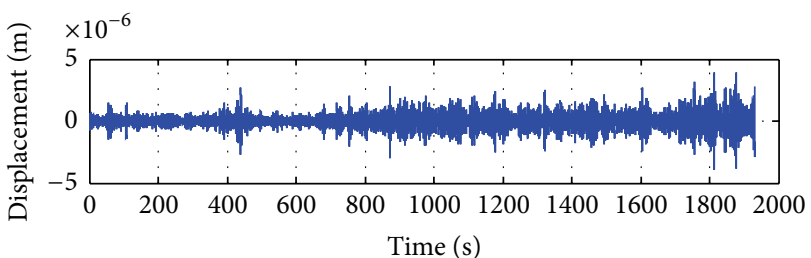

Integrated displacement time history at third floor

(a)

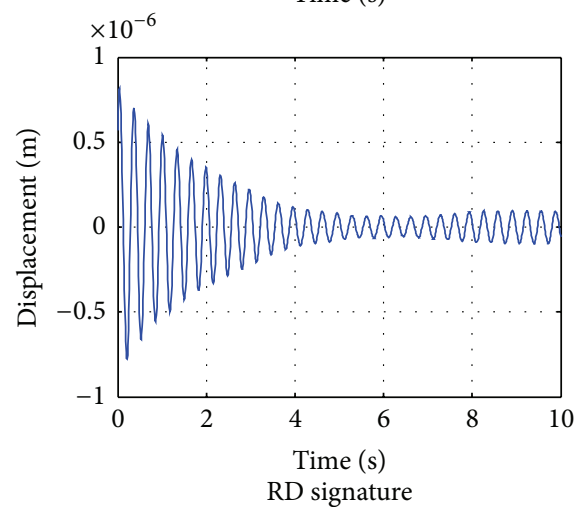

(b)

FIGURE 12: (a) Integrated displacement time histories at each floor in E-W direction and (b) their RD signature plots.

4.1. Estimation of Damping Ratio Using CWT Method through Damped Free Vibration Response. Before applying the twostep procedure to estimate damping ratios using ambient vibration measurements, it is important to prove that if the response is a damped free vibration, then the damping ratio $\varsigma$ of any mode of vibration of a structure can be estimated accurately from the slope of the straight line of the wavelet coefficient modulus cross using (9). This is because a damped free vibration response avoids the effects of uncertainty in evaluation of a damped free vibration response from other 


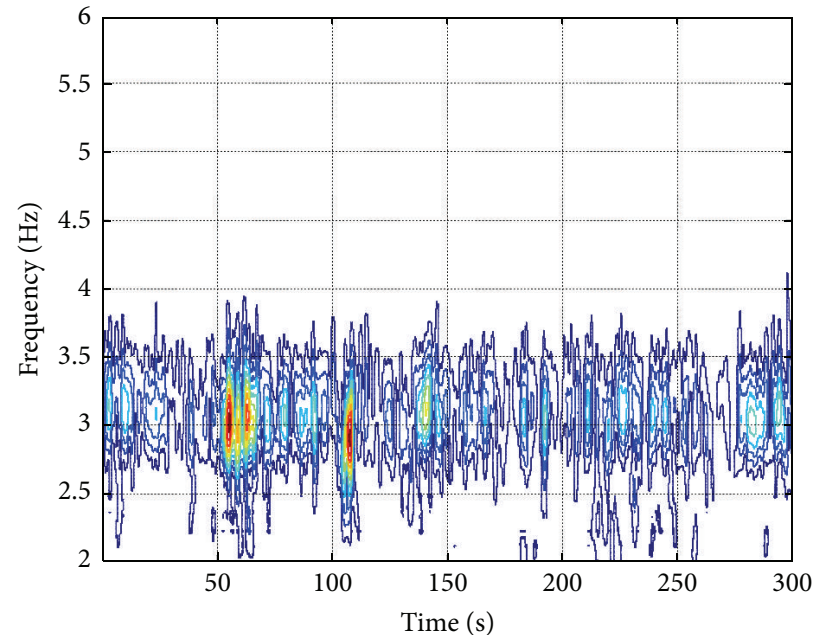

(a) Time-frequency plot of modulus of CWT coefficients for first mode of vibration

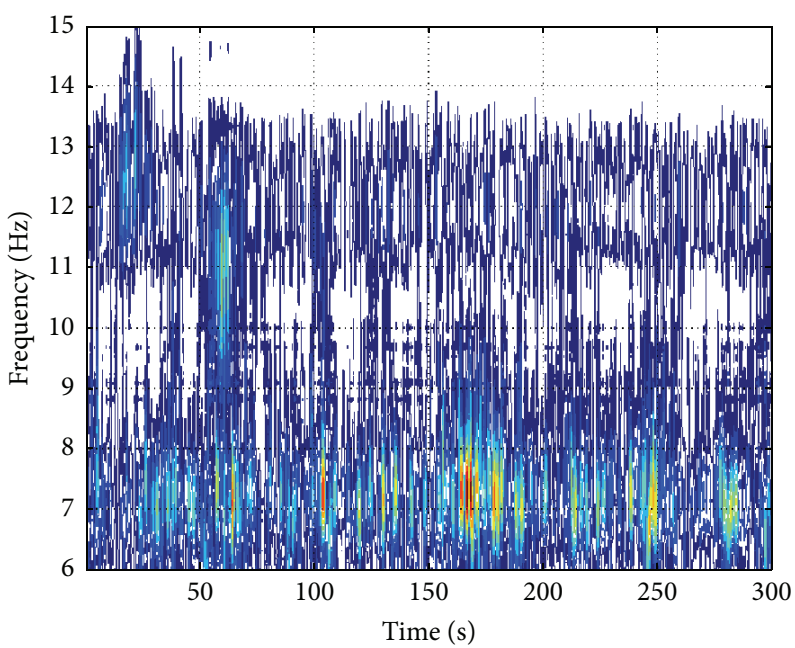

(b) Time-frequency plot of modulus of CWT coefficients for second and third modes of vibration

FIGURE 13: Time-frequency plot of modulus of CWT coefficients.

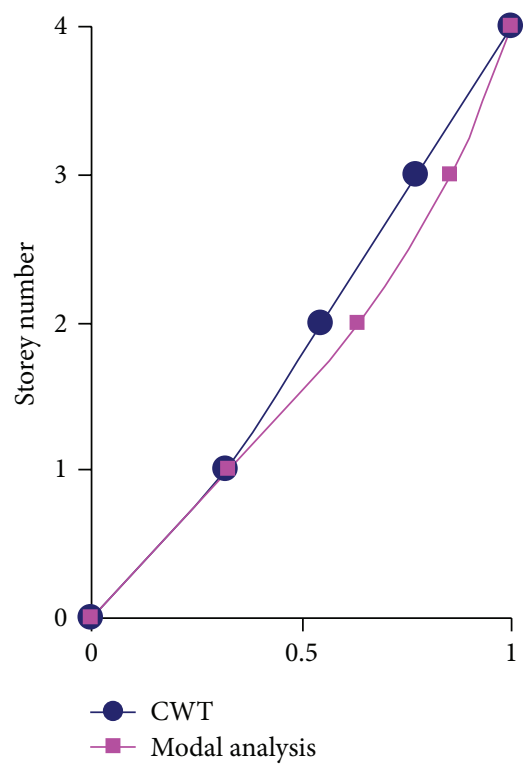

FIGURE 14: Comparison of mode shapes obtained from CWT and modal analysis.

types of vibration responses (e.g., evaluation of a damped free vibration response from an ambient vibration response of a structure using RD method). Therefore, the structure is analyzed for additional 10 seconds after each earthquake to obtain damped free responses at each storey level. Then, the damped free vibration responses are decomposed into a time-frequency domain by using CWT with complex Morlet wavelet.

Figures 3(a), 3(b), and 3(c) show the damped free displacement response at the top storey level after an earthquake, its time-frequency plot, and the extracted window parallel to the frequency axis at the wavelet ridge for 1st mode of vibration, respectively. It is clear from Figures 3(b) and 3(c) that the peak value of the modulus of CWT coefficients corresponds to the frequency of $2.1 \mathrm{~Hz}$ which is very close to the 1st mode frequency obtained from the modal analysis.

As described in Section 3, a window parallel to the time axis at the wavelet ridge is extracted from the time-frequency plot to estimate the damping ratio of the corresponding mode of vibration using (9). Figures $4(\mathrm{a})$ and 4 (b) show the extracted envelope of the CWT coefficient modulus at the frequency of $2.1 \mathrm{~Hz}$ and its semilogarithmic plot for the 1st mode of vibration of the structure, respectively. Furthermore, Figure 4(c) shows the comparison between the damped free vibrational response and the extracted envelope of CWT coefficient modulus. They are in good agreement proving that CWT coefficients are proportional to the instantaneous amplitude of the response. The estimated damping ratio 


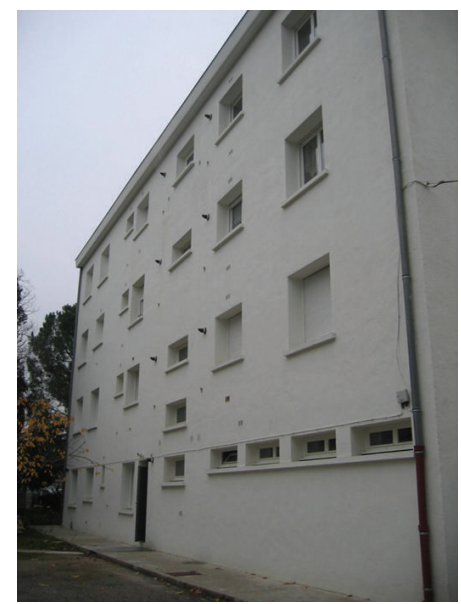

FIGURE 15: 3D view of the building.

corresponding to the 1 st mode is $5.09 \%$, which is very close to the assumed damping ratio of $5 \%$. The difference in the estimation is less than $2 \%$.

\subsection{Estimation of Damping Ratio Using Two-Step Procedure.} Figure 5 summarizes the two-step procedure to estimate damping ratio in this study. Displacement response at the top storey level resulting in the input ground motion is obtained and, subsequently, the RD signature is evaluated using the RD method as shown in Step 1(b). It should be noted that the level crossing triggering technique, which is commonly used in the literature, is adopted in this study. A number of 214 segments are used in evaluation of the RD signature shown in Figure 5.

The $\mathrm{RD}$ signature is then decomposed into timefrequency domain using CWT as shown in Step 2(a). In Step 2(b), a window parallel to the time axis is extracted at the wavelet ridge and then the semilogarithmic plot of the CWT coefficient modulus is obtained as described in Section 4.1. It is clear that the straight line as shown in Figure 4(b) is not observed. As a consequence of that, a straight line is approximated using linear regression to the portion of the curve between two points that are indicated in the black circles in Figure 5. As shown in Figure 5(d), the amplitudes of the first two cycles are not matched well with the wavelet due the edge effect. Therefore, the first point represents the third peak where the amplitude of the response and the real part of the scaled WT coefficient are very close to each other and the second point represents the peak of the last cycle of the response. Finally, the estimated damping ratio is 5.93\% which is $18.7 \%$ higher estimation than the assumed damping ratio of $5 \%$ for the first mode.

Table 1 presents the earthquake number, duration of the ground motion, number of segments used to evaluate the $\mathrm{RD}$ signature, the duration of the $\mathrm{RD}$ signature, estimated damping ratio, estimated period, error in estimation of damping ratio, and the error period of each earthquake.

Figure 6 indicates that the maximum percentage of the error in the estimation of damping ratio is $26 \%$.
4.3. Estimation of Natural Periods and Mode Shapes through Ambient Vibration Measurements. Figure 7 illustrates the procedure used to estimate the natural frequencies of the structure. The displacement response at the top story level shown in Figure 7(a) is decomposed into a time-frequency domain. Figure 7(b) shows the time-frequency plot. The periods are estimated using an extracted window parallel to the frequency axis at a wavelet ridge. Figure 7(c) indicates the wavelet ridges at which the windows are extracted. Figure 8 shows the variation of error in the estimation of 1st mode period of the structure for different ground motions selected in this study. It indicates that the maximum error in the estimation of period is $6.7 \%$. This highlights the capability of CWT method with complex Morlet wavelet to estimate natural periods adequately accurately even using a response, which lasts for relatively short duration.

Furthermore, Figures 7(b) and 7(c) illustrate that the frequency of the second mode of vibration can also be extracted. The extracted frequency is $8.3 \mathrm{~Hz}$, which is very close to the second mode period of $8.2 \mathrm{~Hz}$ obtained from modal analysis. Figure 8 indicates that the maximum percentage of the error in the estimation of natural period is less than $7 \%$.

Figure 9 shows the comparison of the first and second mode shapes extracted using CWT and modal analysis. They are in very good agreement.

\section{Practical Applications in Low-Rise Buildings}

5.1. Picasso Building. Picasso building is a six-storey reinforced concrete structure including one underground storey as shown in Figure 10(a). It is symmetric in plan and elevation. The floor plan is approximately rectangle with dimensions of $45 \mathrm{~m}$ and $14.5 \mathrm{~m}$ in length and width, respectively, as shown in Figure 10(b). In the transverse direction, the building has 2 bays and each bay is $7 \mathrm{~m}$ wide while, in the longitudinal direction, it has 16 bays and each bay is $2.6 \mathrm{~m}$ long. The height of each storey is $3.1 \mathrm{~m}$. The building consists of some interior and exterior infill walls as shown in Figure 10(b). 
TABLE 1: Details of properties.

\begin{tabular}{|c|c|c|c|c|c|c|c|}
\hline $\begin{array}{l}\text { Earthquake } \\
\text { number }\end{array}$ & $\begin{array}{l}\text { Duration } \\
\text { (s) }\end{array}$ & $\begin{array}{l}\text { Number of } \\
\text { segments }\end{array}$ & $\begin{array}{c}\text { Duration of } \\
\text { RD signature (s) }\end{array}$ & $\begin{array}{l}\text { Damping } \\
\text { ratio (\%) }\end{array}$ & $\begin{array}{l}\text { Period } \\
\quad(s)\end{array}$ & $\begin{array}{c}\text { Error in } \\
\text { period } \\
\text { estimation } \\
(\%)\end{array}$ & $\begin{array}{c}\text { Error in } \\
\text { damping } \\
\text { estimation } \\
(\%)\end{array}$ \\
\hline 1 & 53 & 126 & 5,0 & 4,844 & 0,480 & 2,1 & $-3,1$ \\
\hline 2 & 53 & 122 & 3,0 & 5,233 & 0,457 & $-2,8$ & 4,7 \\
\hline 3 & 27 & 84 & 5,0 & 3,980 & 0,472 & 0,4 & $-20,4$ \\
\hline 4 & 27 & 104 & 3,0 & 4,944 & 0,485 & 3,2 & $-1,1$ \\
\hline 5 & 22 & 81 & 3,0 & 4,648 & 0,468 & $-0,4$ & $-7,0$ \\
\hline 6 & 32 & 102 & 7,0 & 4,598 & 0,428 & $-4,6$ & $-8,0$ \\
\hline 7 & 42 & 74 & 3,0 & 4,776 & 0,473 & 0,7 & $-4,5$ \\
\hline 8 & 34 & 144 & 3,0 & 4,469 & 4,950 & 5,3 & $-10,6$ \\
\hline 9 & 38 & 142 & 1,5 & 4,396 & 0,485 & 3,2 & $-12,1$ \\
\hline 10 & 26 & 82 & 3,5 & 4,436 & 0,502 & 6,7 & $-11,3$ \\
\hline 11 & 30 & 76 & 2,0 & 4,587 & 0,485 & 3,2 & $-8,3$ \\
\hline 12 & 42 & 100 & 5,0 & 4,197 & 0,490 & 4,3 & $-16,1$ \\
\hline 13 & 37 & 134 & 2,5 & 5,277 & 0,465 & $-1,1$ & 5,5 \\
\hline 14 & 38 & 78 & 2,0 & 4,529 & 0,463 & $-1,4$ & $-9,4$ \\
\hline 15 & 49 & 154 & 3,0 & 4,117 & 0,472 & 0,4 & $-17,7$ \\
\hline 16 & 48 & 182 & 3,0 & 4,312 & 0,473 & 0,7 & $-13,8$ \\
\hline 17 & 56 & 150 & 3,0 & 5,520 & 0,472 & 0,4 & 10,4 \\
\hline 18 & 88 & 292 & 2,0 & 4,514 & 0,473 & 0,7 & $-9,7$ \\
\hline 19 & 88 & 256 & 2,0 & 4,355 & 0,447 & $-5,0$ & $-12,9$ \\
\hline 20 & 65 & 234 & 4,0 & 4,140 & 0,458 & $-2,5$ & $-17,2$ \\
\hline 21 & 68 & 236 & 2,0 & 4,897 & 0,482 & 2,5 & $-2,1$ \\
\hline 22 & 68 & 214 & 3,0 & 4,990 & 0,458 & $-2,5$ & $-0,2$ \\
\hline 23 & 73 & 228 & 5,0 & 5,598 & 0,475 & 1,1 & 12,0 \\
\hline 24 & 73 & 214 & 2,0 & 4,805 & 0,465 & $-1,1$ & $-3,9$ \\
\hline 25 & 23 & 76 & 2,0 & 4,650 & 0,498 & 6,0 & $-7,0$ \\
\hline 26 & 22 & 74 & 3,0 & 5,132 & 0,452 & $-3,9$ & 2,6 \\
\hline 27 & 103 & 306 & 3,0 & 4,433 & 0,483 & 2,8 & $-11,3$ \\
\hline 28 & 111 & 334 & 2,5 & 6,300 & 0,458 & $-2,5$ & 26,0 \\
\hline 29 & 111 & 356 & 2,0 & 5,003 & 0,447 & $-5,0$ & 0,1 \\
\hline 30 & 98 & 258 & 2,5 & 4,959 & 0,458 & $-2,5$ & $-0,8$ \\
\hline 31 & 67 & 188 & 3,0 & 5,933 & 0,460 & $-2,1$ & 18,7 \\
\hline 32 & 67 & 186 & 3,0 & 4,336 & 0,475 & 1,1 & $-13,3$ \\
\hline 33 & 59 & 178 & 2,5 & 4,732 & 0,485 & 3,2 & $-5,4$ \\
\hline 34 & 102 & 292 & 3,0 & 4,433 & 0,478 & 1,8 & $-11,4$ \\
\hline 35 & 46 & 132 & 4,0 & 4,160 & 0,472 & 0,4 & $-16,8$ \\
\hline 36 & 33 & 84 & 3,5 & 5,460 & 0,485 & 3,2 & 9,2 \\
\hline 37 & 43 & 116 & 4,0 & 4,854 & 0,458 & $-2,5$ & $-2,9$ \\
\hline 38 & 47 & 136 & 2,0 & 4,807 & 0,505 & 6,4 & $-3,9$ \\
\hline 39 & 70 & 246 & 2,5 & 5,690 & 0,485 & 3,2 & 13,8 \\
\hline 40 & 47 & 160 & 3,5 & 5,423 & 0,474 & 0,9 & 8,5 \\
\hline 41 & 67 & 246 & 2,5 & 4,424 & 0,465 & $-1,1$ & $-11,5$ \\
\hline 42 & 67 & 226 & 3,0 & 5,338 & 0,465 & $-1,1$ & 6,8 \\
\hline 43 & 40 & 100 & 4,0 & 4,639 & 0,463 & $-1,4$ & $-7,2$ \\
\hline 44 & 39 & 120 & 5,0 & 4,232 & 0,482 & 2,5 & $-15,4$ \\
\hline 45 & 48 & 130 & 2,0 & 5,627 & 0,437 & $-5,0$ & 12,5 \\
\hline 46 & 67 & 200 & 2,5 & 4,747 & 0,458 & $-2,5$ & $-5,1$ \\
\hline
\end{tabular}



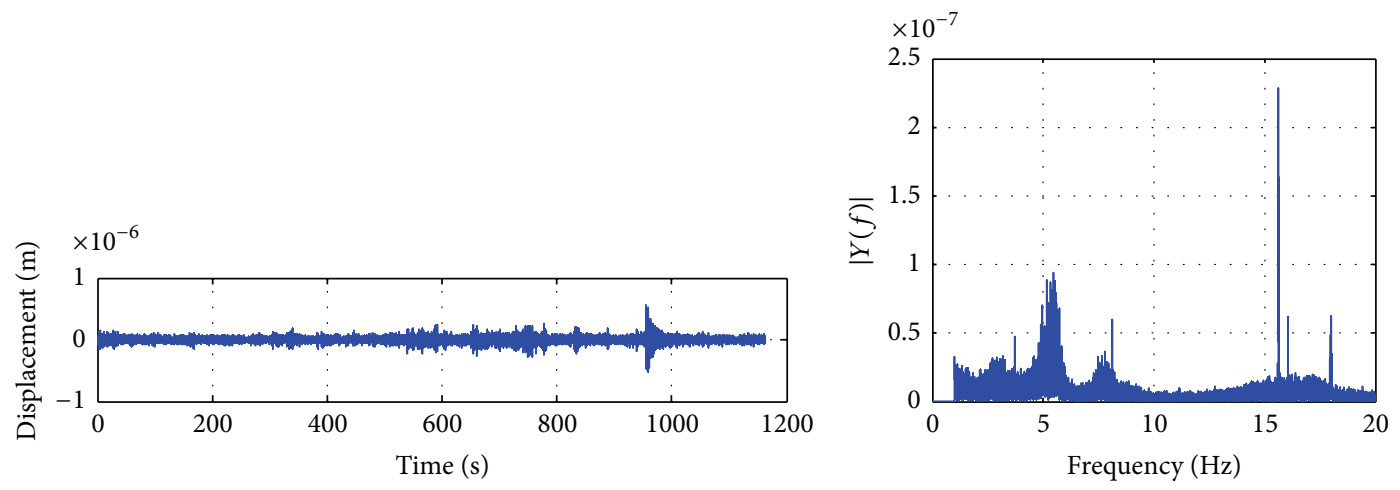

Integrated displacement time history at first floor
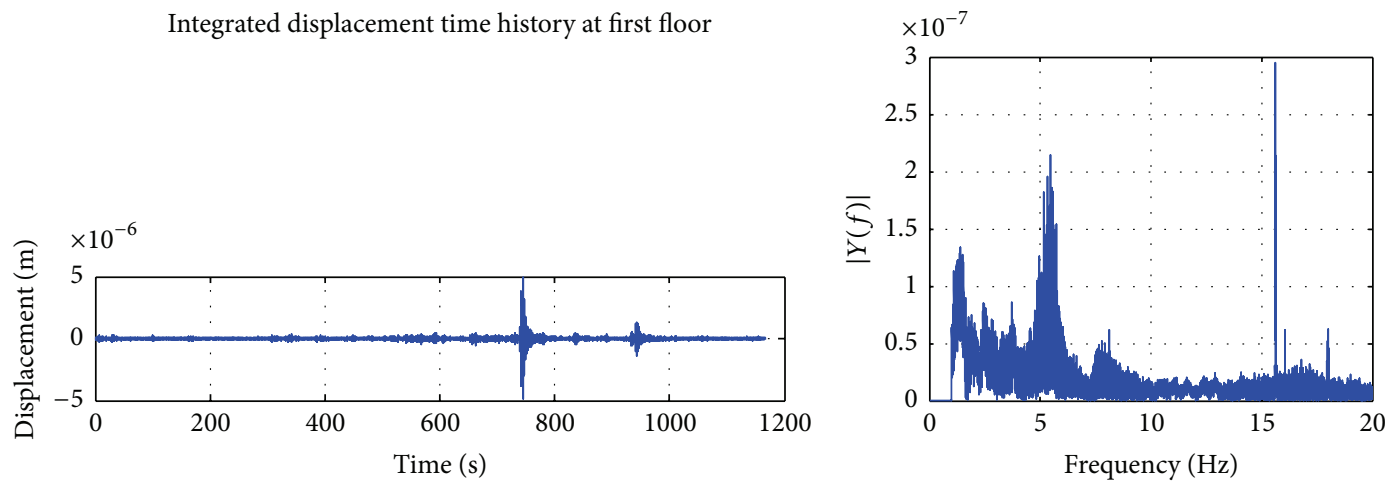

Integrated displacement time history at second floor

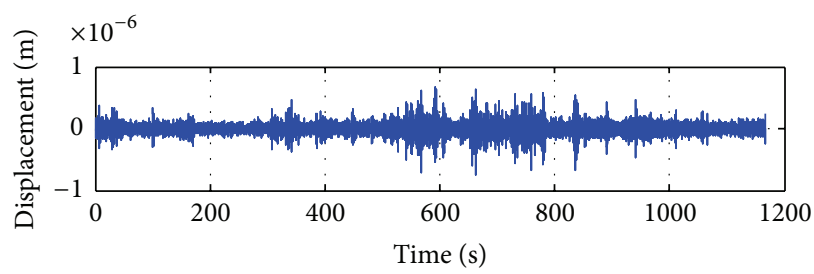

Integrated displacement time history at third floor

(a)

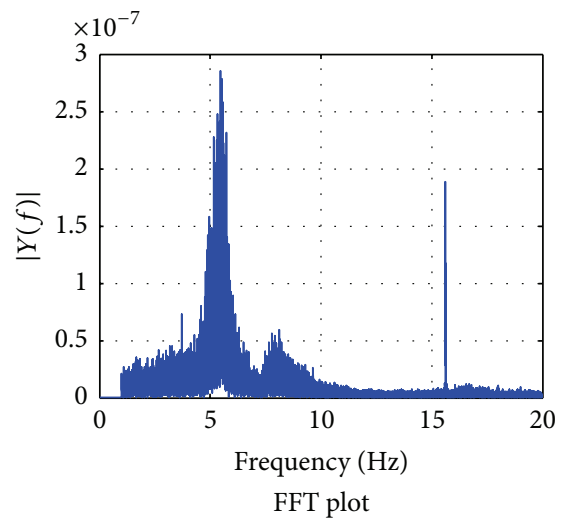

(b)

FIGURE 16: (a) Integrated displacement time histories at each floor in E-W direction and (b) their fast Fourier transformation (FFT) plots.

Ambient excitations are measured at each floor level of the building and the ground during the field test by triaxial seismometers (CMG-6TD). They are placed approximately at the centre of the each floor plan. All data is acquired at the frequency of $100 \mathrm{~Hz}$ for the period of 1800 seconds. The recorded data is then preprocessed using a band-pass filter (Chebyshev) at the specified frequency range from 2 to $15 \mathrm{~Hz}$ to remove the nonzero mean noise and the uncorrelated noise to the structural response. Figure 11 illustrates the filtered velocity time history at each story level in East-West (E-W) direction and their fast Fourier Transformation (FFT) plots. Furthermore, the displacement time histories are obtained by integrating the filtered velocity time histories in time domain using a trapezoid integration approach. They are shown in Figure 12(a).
5.1.1. Extracting Modal Parameters. Ambient vibration response of this structure is sensitive in the longitudinal direction (E-W direction). Therefore, modal properties only in the longitudinal direction have been identified and discussed in this part of the study.

In order to estimate damping ratios, two-step procedure, which is described in Section 4, is used. As the first step of the two-step procedure, RD signatures are evaluated from the displacement time histories at different storey levels using the RD method. For this evaluation, the length of each RD signature is set to be 10 seconds (1000 samples). A level crossing triggering condition is used with the optimal value of the triggering level as discussed in Section 2. Figure 12(b) shows the resultant RD signatures of the displacement time histories. They clearly illustrate the damped free response. 

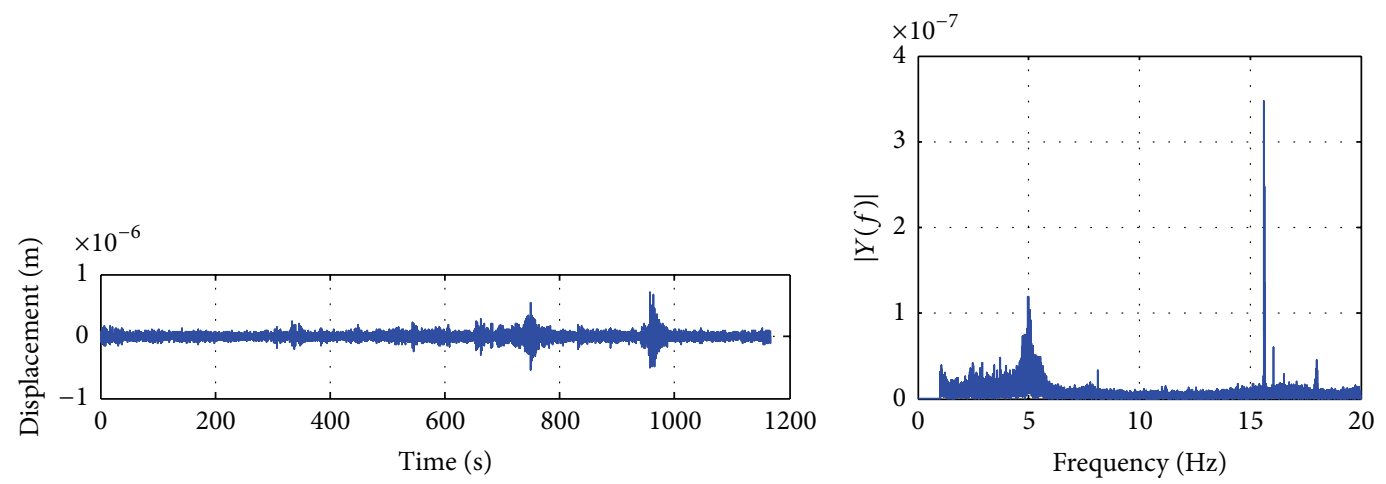

Integrated displacement time history at first floor
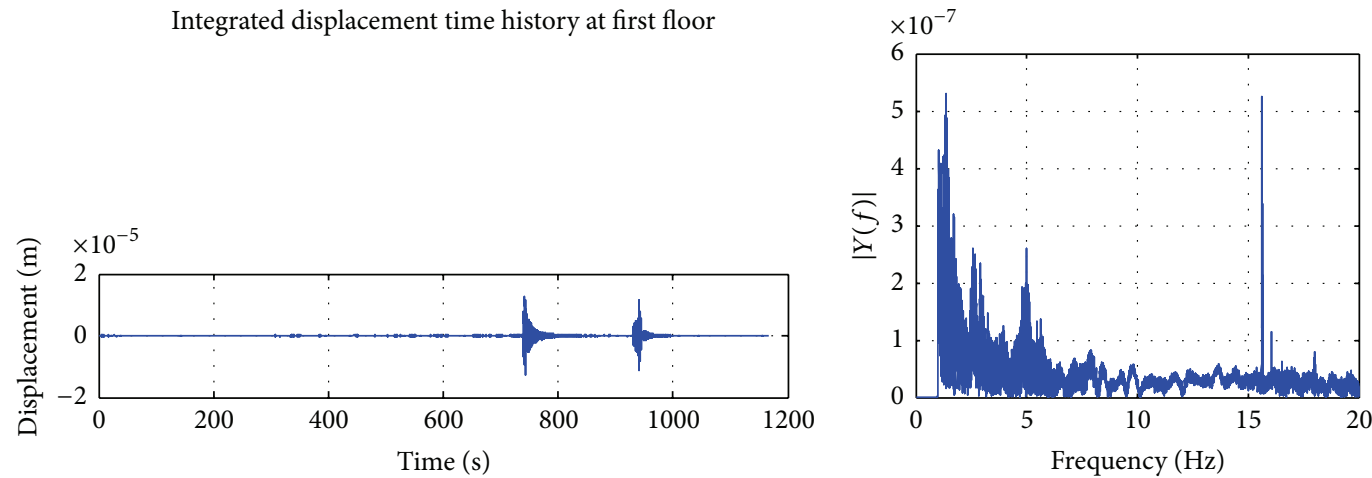

Integrated displacement time history at first floor

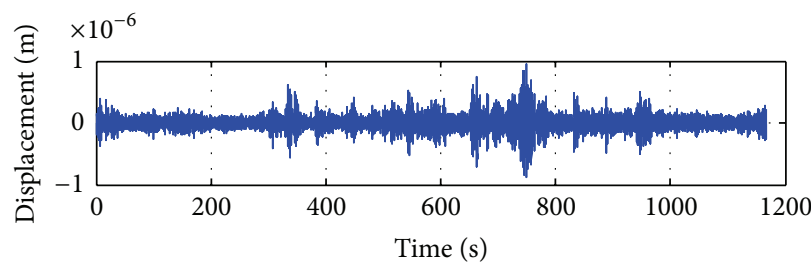

Integrated displacement time history at first floor

(a)

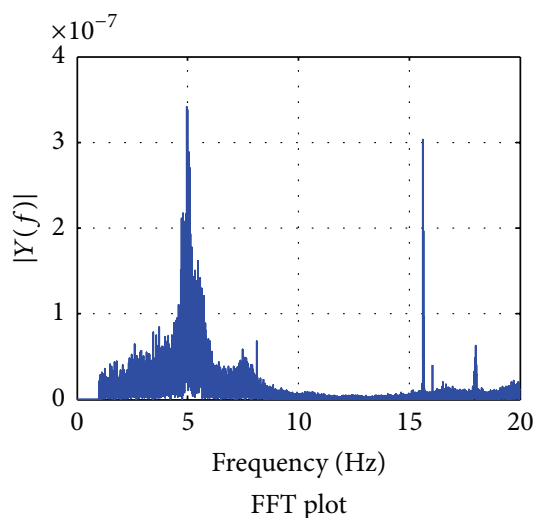

(b)

FIGURE 17: (a) Integrated displacement time histories at each floor in N-S direction and (b) their fast Fourier transformation (FFT) plots.

TABLE 2: Comparison of the damping ratios estimated using the two approaches.

\begin{tabular}{lcccccc}
\hline Floor number & \multicolumn{2}{c}{ Mode 1 } & \multicolumn{3}{c}{ Mode 2 } \\
& Damping (two-step) & Damping (RD only) & Difference (\%) & Damping (two-step) & Damping (RD only) & Difference (\%) \\
\hline 1 & 2.011 & 1.875 & 6.8 & 3.929 & 4.333 & 10.3 \\
2 & 2.111 & 1.932 & 8.0 & 3.581 & 3.650 & 1.9 \\
3 & 1.986 & 2.051 & 3.3 & 3.468 & 3.250 & 6.3 \\
4 & 2.600 & 2.805 & 8.5 & 3.495 & 3.533 \\
\hline
\end{tabular}

To estimate the damping ratio associated with the first translational mode in longitudinal direction using (9), the semilogarithmic plot is obtained by extracting a window parallel to time axis from each time-frequency plot at the frequency of $3.03 \mathrm{~Hz}$. The damping ratio associated with second translational mode is estimated using the same approach but filtering out the first mode frequency content from the displacement time histories.

Furthermore, damping ratios are also estimated using only the RD signatures. However, only for this case, damped free response data incorporated with any natural period is extracted from the integrated displacement histories by 

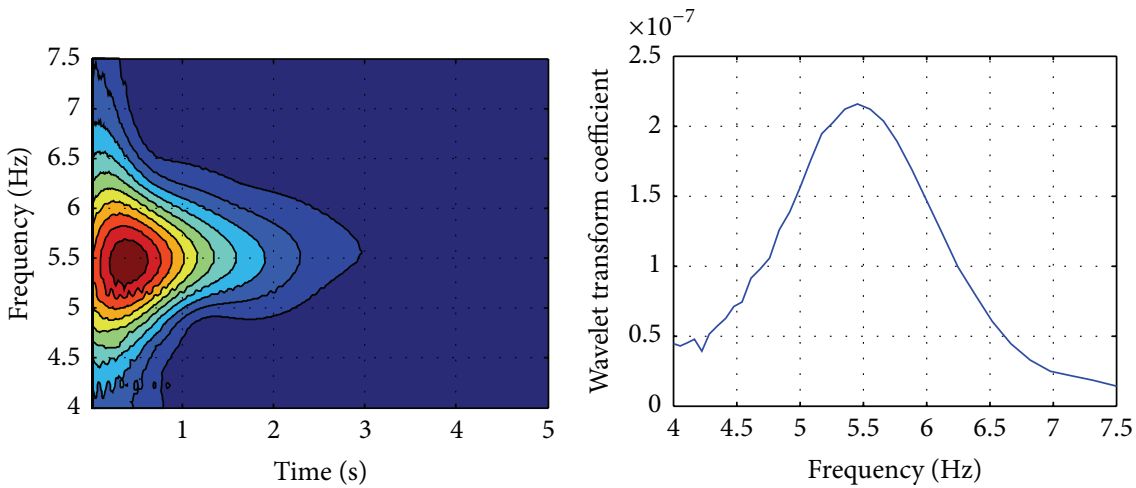

(a) E-W direction
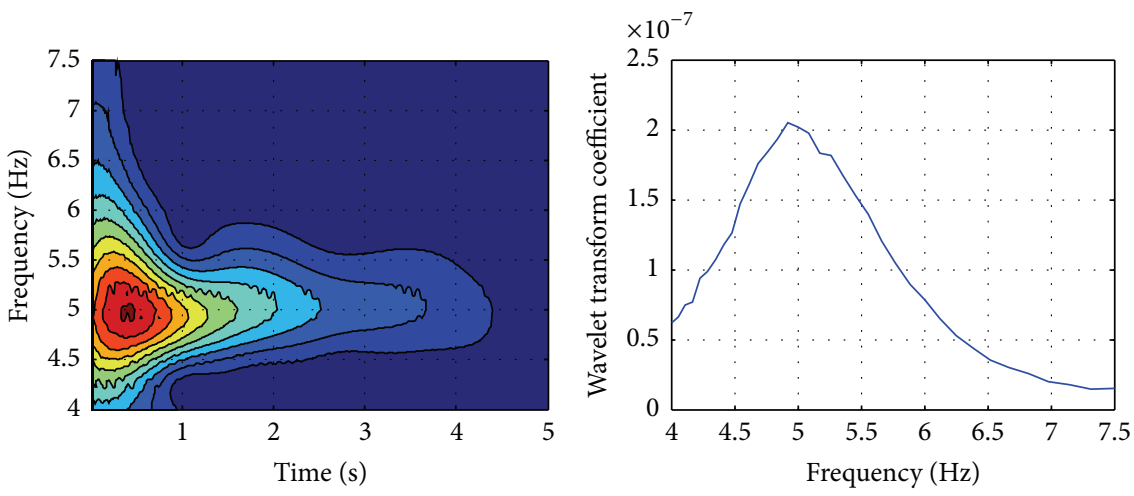

(b) N-S direction

FIGURE 18: Time-frequency plot of RD signatures evaluated from displacement time histories at 3rd storey level in (a) the E-W and (b) N-S directions.

TABLE 3: Comparison of the periods extracted from CWT method and modal analysis.

\begin{tabular}{lccc}
\hline Mode & $\begin{array}{c}\text { Period (s)- } \\
\text { numerical }\end{array}$ & $\begin{array}{c}\text { Period (s)- } \\
\text { CWT }\end{array}$ & $\begin{array}{c}\text { Difference } \\
(\%)\end{array}$ \\
\hline 1 & 0.338 & 0.330 & 2.4 \\
2 & 0.126 & 0.135 & 5.5 \\
3 & 0.087 & 0.090 & 4.3 \\
\hline
\end{tabular}

band-pass filtering before the RD method is used. It should be noted that RD signatures shown in Figure 12(a) do not represent the damped free SDOF response. They represent the MDOF response used to estimate the damping ratios by two-step procedure ( $\mathrm{RD}+\mathrm{CWT})$. Table 2 compares the resultant damping ratios estimated using the two approaches. The maximum difference of $8.5 \%$ is observed at the 4 th storey level for the 1st mode of vibration while it is $10.3 \%$ for the second mode of vibration.

The frequencies and mode shapes are extracted directly by decomposing the part of first 300 seconds of the velocity time histories at different storey levels into time-frequency domain using CWT with complex Morlet wavelet. Figure 13 shows the time-frequency plots obtained by decomposing of the 4 th floor record. It indicates that the frequencies of the first, second, and third translational modes in the longitudinal direction of the building can be identified clearly. Table 3 compares the frequencies estimated using CWT method and the modal analysis. It should be noted that the natural periods tabulated in Table 3 referring the CWT are the average periods obtained from the four records for each mode of vibration.

Figure 14 illustrates the comparison of the first mode shape extracted from CWT method and the modal analysis. They are in good agreement. However, reasonably good estimation for the second mode shape could not be obtained using the approach described in Sections 3 and 4.

5.2. Sauvy Building. Sauvy building is a four-storey masonry structure as shown in Figure 15. It is also regular in plan and elevation. The floor plan is approximately rectangle with dimensions of $22 \mathrm{~m}$ and $9 \mathrm{~m}$ in length and width, respectively.

Ambient vibrations are measured at each floor level of the building and the ground using triaxial seismometers (CMG6TD). The seismometers are placed approximately at the centre of each floor plan. All data is acquired at the frequency of $100 \mathrm{~Hz}$ for the period of 19 minutes. As described in the previous section, the recorded data is preprocessed using a band-pass filter (Chebyshev) at the specified frequency range from 1 to $20 \mathrm{~Hz}$ to remove the nonzero mean noise 

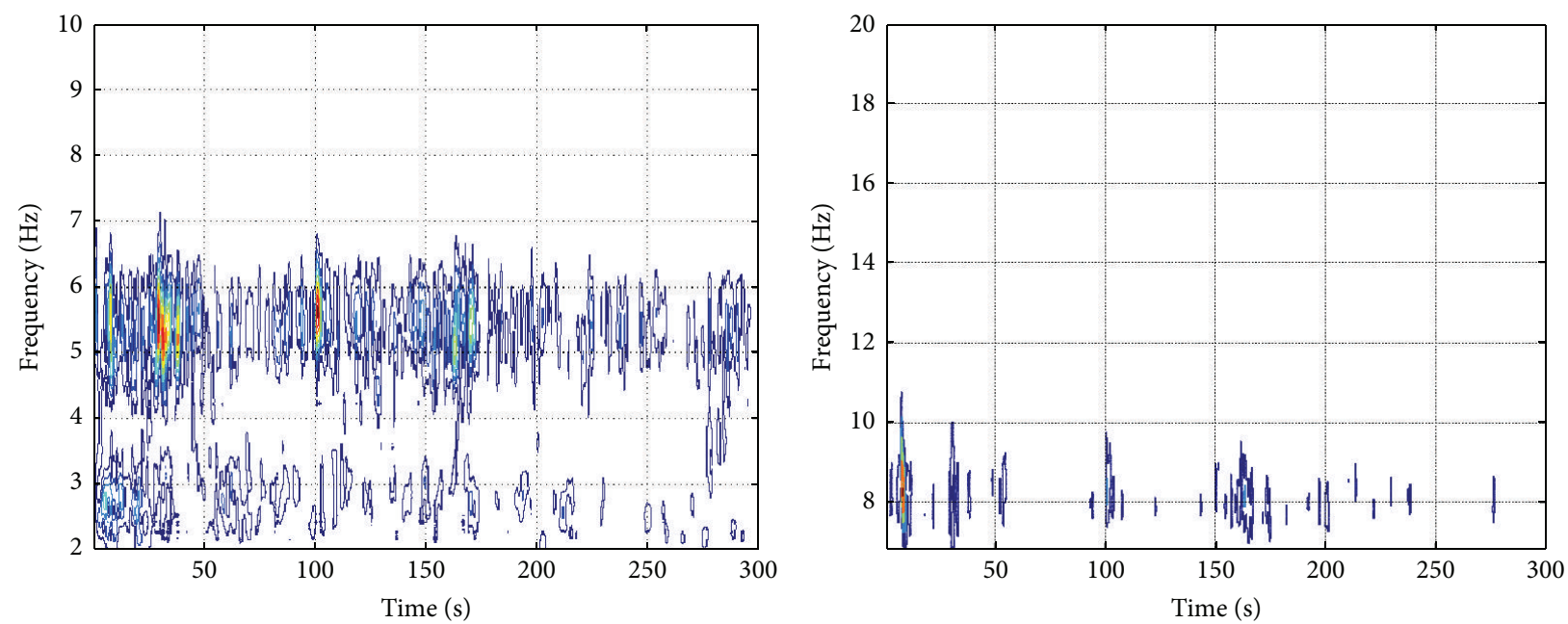

(a) E-W direction
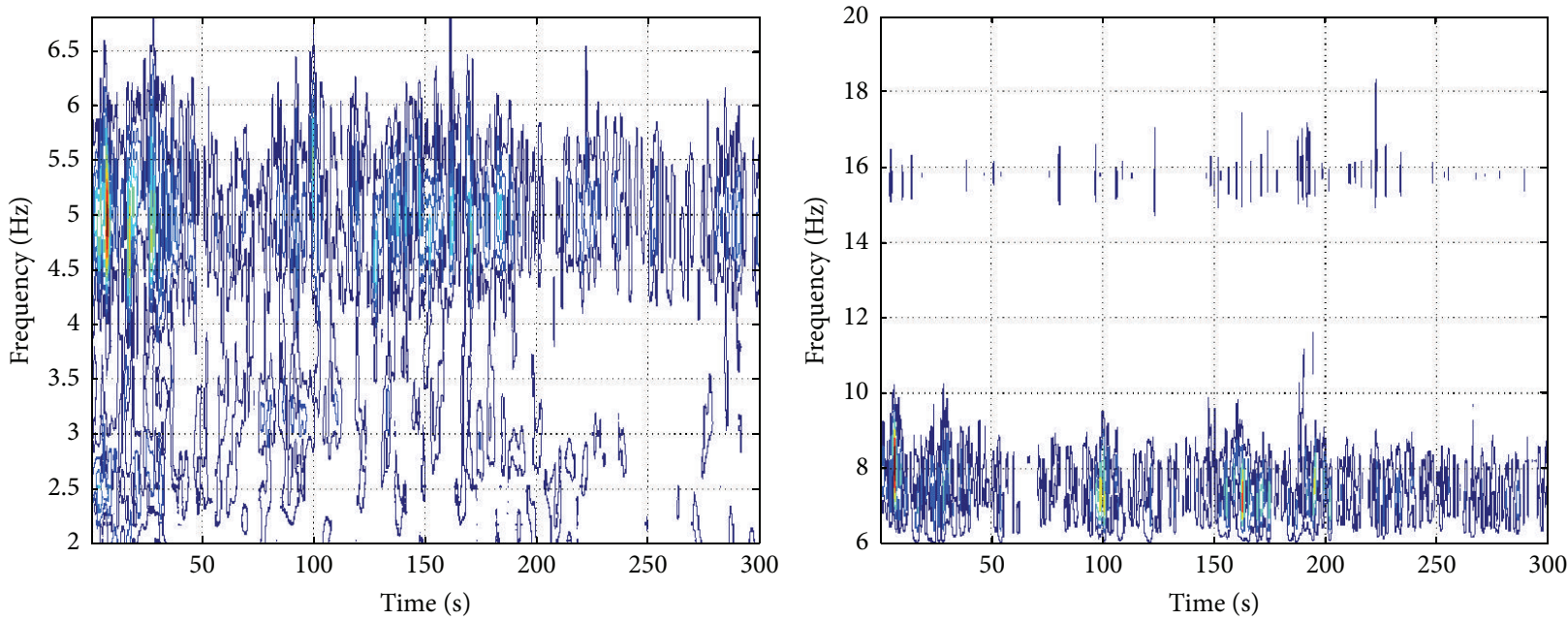

(b) N-S direction

FIGURE 19: Time-frequency plot of modulus of CWT coefficients in (a) E-W direction and (b) N-S direction.

TABLE 4: Comparison of the damping ratios estimated using the two approaches.

\begin{tabular}{|c|c|c|c|c|c|c|}
\hline \multirow[b]{2}{*}{ Floor number } & \multicolumn{3}{|c|}{ 1st translational mode in E-W direction } & \multicolumn{3}{|c|}{ 1st translational mode in N-S direction } \\
\hline & $\begin{array}{c}\text { Damping } \\
(\mathrm{RD}+\mathrm{CWT}) \\
\end{array}$ & $\begin{array}{l}\text { Damping } \\
\text { (RD only) }\end{array}$ & $\begin{array}{c}\text { Difference } \\
(\%)\end{array}$ & $\begin{array}{c}\text { Damping } \\
(\mathrm{RD}+\mathrm{CWT}) \\
\end{array}$ & $\begin{array}{l}\text { Damping } \\
\text { (RD only) } \\
\end{array}$ & $\begin{array}{c}\text { Difference } \\
(\%)\end{array}$ \\
\hline 1 & 2.950 & 3.006 & 1.9 & 2.069 & 2.156 & 4.2 \\
\hline 2 & 2.526 & 3.079 & 21.9 & 2.195 & 2.597 & 18.3 \\
\hline 3 & 2.761 & 2.710 & 1.8 & 2.109 & 2.100 & 0.4 \\
\hline
\end{tabular}

and the uncorrelated noise to the structural response before integrating the velocity time history into corresponding displacement time history.

Figures 16 and 17 illustrate the integrated displacement time histories at each storey level in East-West (E-W) and North-South (N-S) directions and their FFT plots, respectively.
5.2.1. Extracting Modal Parameters. RD signatures are evaluated by using a similar procedure described in previous section. Figure 18 shows the resultant time-frequency plot of RD signatures evaluated from displacement time histories at $3 \mathrm{rd}$ storey level in the E-W and N-S directions and the extracted envelopes parallel to frequency axis at wavelet ridges. This illustrates clearly that even though the 1st translational modes 
TABLE 5: Extracted the frequencies from CWT method.

\begin{tabular}{lcc}
\hline Mode & $\begin{array}{c}\text { Frequency }(\mathrm{Hz}) \\
\text { longitudinal }(\mathrm{E}-\mathrm{W})\end{array}$ & $\begin{array}{c}\text { Frequency }(\mathrm{s}) \\
\text { transverse }(\mathrm{N}-\mathrm{S})\end{array}$ \\
\hline 1 & 5.50 & 5.00 \\
2 & 8.33 & 7.56 \\
3 & - & 15.79 \\
\hline
\end{tabular}

in E-W and N-S directions are very close $(5.5 \mathrm{~Hz}$ and $5.0 \mathrm{~Hz}$, resp.), each RD signature is not contaminated by the other component of the response. Therefore, the effect of close mode response could be minimized in the damping estimation. Table 4 compares the resultant damping ratios estimated using the two approaches. The maximum difference of $18.3 \%$ is observed at the 4th storey level.

The periods are extracted directly by decomposing the part of first 300 seconds of the displacement histories at different storey levels into time-frequency domain using CWT. Figures 19(a) and 19(b) show the time-frequency plots obtained from the record at the 3rd floor in identifying the first, second, and third translational modes in the longitudinal (E-W) and transverse (N-S) directions of the building, respectively. Table 5 presents the periods estimated using CWT.

\section{Conclusion}

This study mainly investigates the capability of the continuous wavelet transformation (CWT) method using Morlet wavelet in estimation of modal properties of low-rise buildings. For this purpose, a numerical and two practical applications are used. Based on the results of the applications following conclusions can be drawn.

Based on the results of numerical application in fivestorey frame building, it can be concluded that the CWT method can estimate the modal properties accurately when the free decay response of a MDOF system is analyzed. Furthermore, the two-step procedure can estimate the damping ratio of any mode of vibration with reasonable good accuracy using ambient vibration measurement. However, a scatter in estimation of damping ratio is observed with the maximum error of $26 \%$ when the two-step procedure is used. This could be due to the fact that, in damping estimation, the evaluation of RD signature for such a short duration record does not represent truly the free decay response of the structure.

Based on the results of analyzing ambient vibration measurements, recorded in low-rise buildings, using the CWT method, natural frequencies of higher modes of translational vibration can be extracted accurately compared with the results from modal analysis. However, it is difficult to estimate the higher mode shapes using ambient vibration measurements with the approach used in this study. More investigation is required to establish a methodology to estimate the higher mode shapes accurately using CWT method. Furthermore, the damping ratios estimated using two steps procedure agree well with those obtained from the RD method.

\section{Conflict of Interests}

The authors declare that there is no conflict of interests regarding the publication of this paper.

\section{Acknowledgments}

This work has been supported by French Research National Agency (ANR) through RiskNat program (Project URBASIS $n^{\circ}$ ANR-09-RISK-009), by European Union through SISPYR Interreg Project (POCTEFA 2007-2013 no. 73/08) and by Languedoc-Roussillon Regional Council.

\section{References}

[1] T.-H. Le and Y. Tamura, "Modal identification of ambient vibration structure using frequency domain decomposition and wavelet transform," in Proceedings of the 7th Asia-Pacific Conference on Wind Engineering (APCWE-VII '09), pp. 8-12, Taipei, Taiwan, November 2009.

[2] M. Meo, G. Zumpano, X. Meng, E. Cosser, G. Roberts, and A. Dodson, "Measurements of dynamic properties of a medium span suspension bridge by using the wavelet transforms," Mechanical Systems and Signal Processing, vol. 20, no. 5, pp. 11121133, 2006.

[3] R. Brincker, L. Zhang, and P. Andersen, "Modal identification of output-only systems using frequency domain decomposition," Smart Materials and Structures, vol. 10, no. 3, pp. 441-445, 2001.

[4] R. Brincker, C. E. Ventura, and P. Andersen, "Damping estimation by frequency domain decomposition," in Proceedings of the 19th International Modal Analysis Conference (IMAC '01), pp. 698-703, 2001.

[5] H. A. Cole, "On-line failure detection and damping measurements of aerospace structures by random decrement signature," NASA CR-2205, 1973.

[6] S. R. Ibrahim, "Random decrement technique for modal identification of structures," Journal of Spacecraft and Rockets, vol. 14, no. 11, pp. 696-700, 1977.

[7] J.-N. Juang and R. S. Pappa, "An eigensystem realization algorithm for modal parameter identification and model reduction," AIAA Journal of Guidance, Control, and Dynamics, vol. 8, no. 5, pp. 620-627, 1985.

[8] W. J. Staszewski, "Identification of damping in MDOF systems using time-scale decomposition," Journal of Sound and Vibration, vol. 203, no. 2, pp. 283-305, 1997.

[9] S. Hans, E. Ibraim, S. Pernot, C. Boutin, and C.-H. Lamarque, "Damping identification in multi-degree-of-freedom system via a wavelet-logarithmic decrement-part 2: study of a civil engineering building," Journal of Sound and Vibration, vol. 235, no. 3, pp. 375-403, 2000.

[10] C.-H. Lamarque, S. Pernot, and A. Cuer, "Damping identification in multi-degree-of-freedom systems via a waveletlogarithmic decrement. Part 1. Theory," Journal of Sound and Vibration, vol. 235, no. 3, pp. 361-374, 2000.

[11] M.-N. Ta and J. Lardis, "Identification of weak nonlinearities on damping and stiffness by the continuous wavelet transform," Journal of Sound and Vibration, vol. 293, no. 1-2, pp. 16-37, 2006.

[12] J. C. S. Yang, N. G. Dagalakis, J. C. Everstine, and Y. F. Wang, "Measurement of structural damping using the random decrement technique," Shock and Vibration Bulletin, vol. 53, no. 4, pp. 63-71, 1983. 
[13] A. Kareem and K. Gurley, "Damping in structures: its evaluation and treatment of uncertainty," Journal of Wind Engineering and Industrial Aerodynamics, vol. 59, no. 2-3, pp. 131-157, 1996.

[14] J. K. Vandiver, A. B. Dunwoody, R. B. Campbell, and M. F. Cook, "A mathematical basis for the random decrement vibration signature analysis technique," Journal of Mechanical Design, vol. 104, pp. 307-313, 1982.

[15] N.E. Bedewi, The mathematical foundation of the auto and crossrandom decrement techniques and the development of a system identification technique for the detection of structural deterioration [Ph.D. thesis], Department of Mechanical Engineering, University of Maryland, College Park, Md, USA, 1986.

[16] N. E. Huang, Z. Shen, S. R. Long et al., "The empirical mode decomposition and the Hilbert spectrum for nonlinear and non-stationary time series analysis," Proceedings of the Royal Society of London Series A, vol. 454, no. 1971, pp. 903-995, 1998.

[17] C. S. Huang and C. H. Yeh, "Some properties of randomdec signatures," Mechanical Systems and Signal Processing, vol. 13, no. 3, pp. 491-507, 1999. 

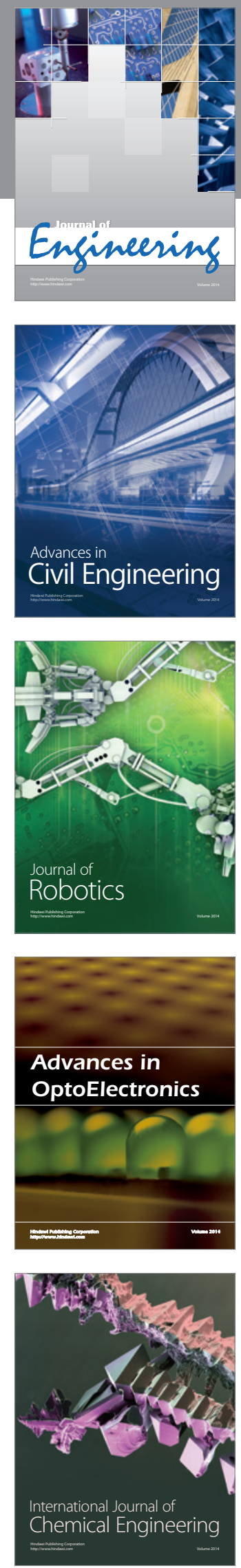

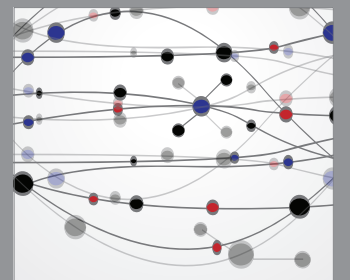

The Scientific World Journal
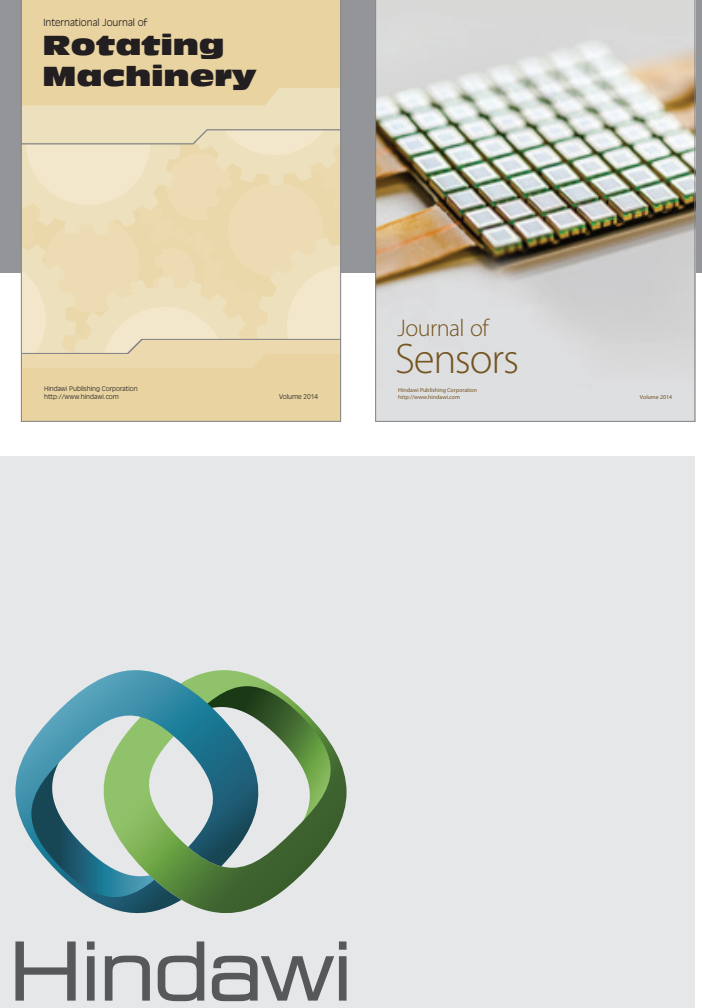

Submit your manuscripts at http://www.hindawi.com
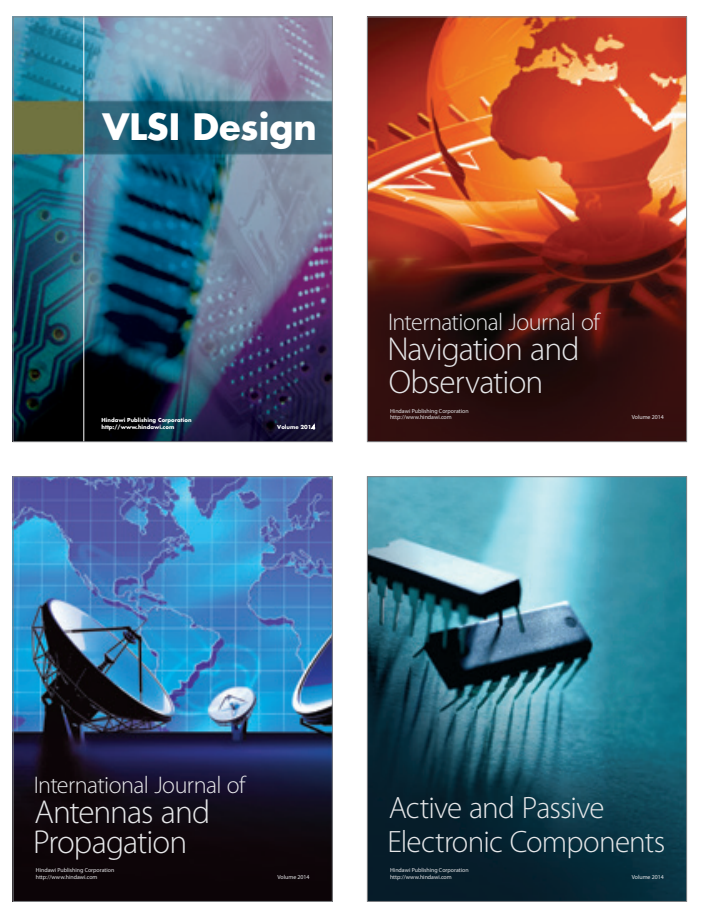
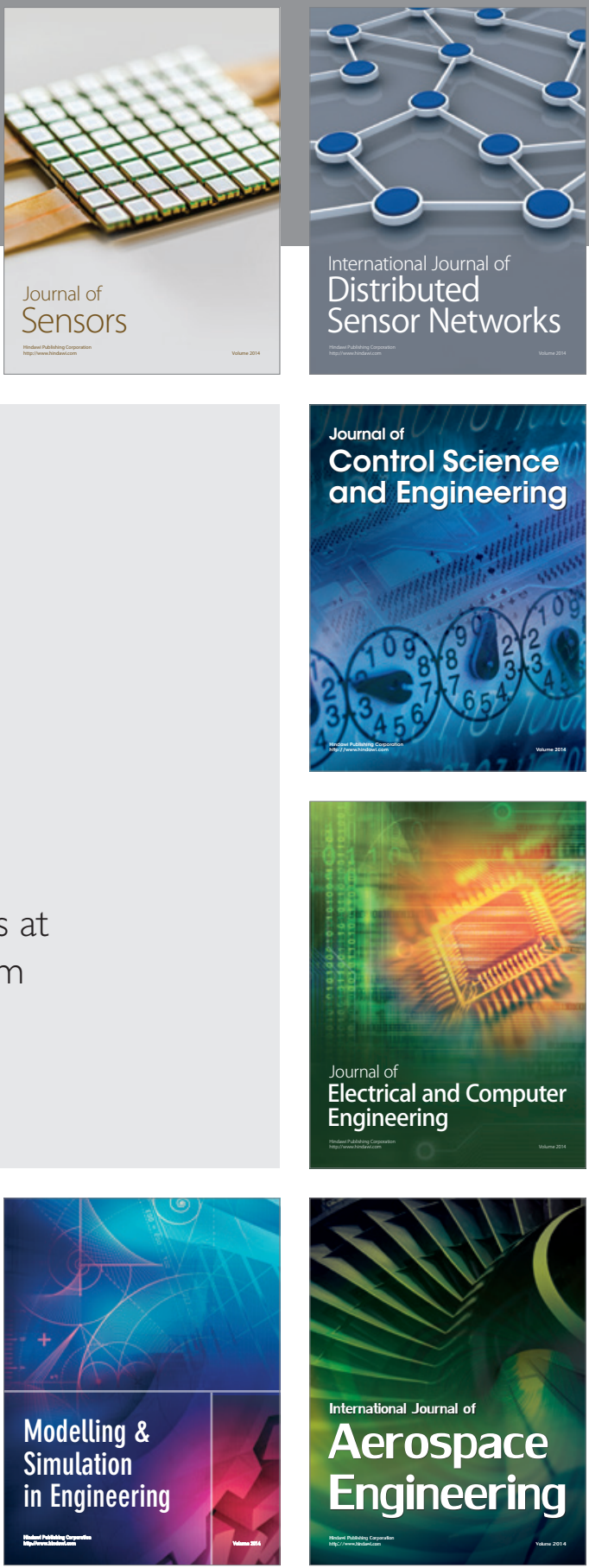

Journal of

Control Science

and Engineering
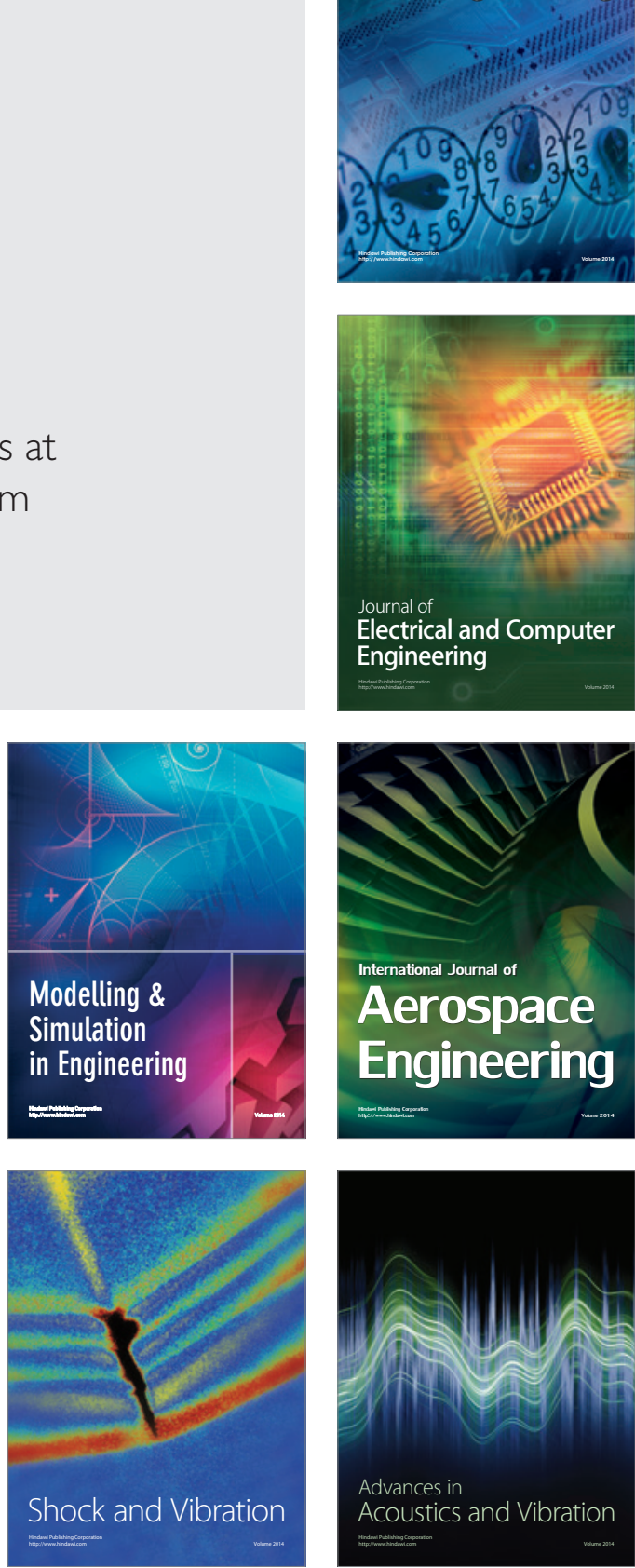